\title{
Synthesis and Biological Evaluation of New Eugenol-Derived 1,2,3-Triazoles as Antimycobacterial Agents
}

\author{
Thiago dos Santos, ${ }^{a}$ Camila M. Coelho, ${ }^{\oplus a}$ Thiago C. Elias, ${ }^{b}$ Fallon S. Siqueira, ${ }^{c}$ \\ Eloísa S. S. D. Nora,$^{c}$ Marli M. A. de Campos, ${ }^{c}$ Gabriel A. P. de Souza, ${ }^{d}$ \\ Luiz F. L. Coelho ${ }^{d}$ and Diogo T. Carvalho ${ }^{\circledR} * a$ \\ ${ }^{a}$ Departamento de Alimentos e Medicamentos, Faculdade de Ciências Farmacêuticas, \\ Universidade Federal de Alfenas, 37130-001 Alfenas-MG, Brazil \\ ${ }^{b}$ Laboratório de Modelagem Molecular e Simulação Computacional, \\ Universidade Federal de Alfenas, 37130-001 Alfenas-MG, Brazil \\ ${ }^{c}$ Departamento de Análises Clínicas e Toxicológicas, Universidade Federal de Santa Maria, \\ 97105-900 Santa Maria-RS, Brazil \\ ${ }^{d}$ Departamento de Microbiologia e Imunologia, Instituto de Ciências Biomédicas, \\ Universidade Federal de Alfenas, 37130-001 Alfenas-MG, Brazil
}

\begin{abstract}
Eugenol has diverse biological properties including antimycobacterial activity, and the triazole ring is an important heterocycle in antimycobacterial compounds. Therefore, this research aimed to synthesize novel eugenol-derived 1,2,3-triazole as antimycobacterial agents with interesting cytotoxic profile and pharmacological assets. Sixteen compounds were obtained and characterized by nuclear magnetic resonance (NMR), infrared (IR), and high-resolution mass spectrometry (HRMS). Among them, the best growth inhibition properties from a microdilution assay were observed for three derivatives: a benzylic ether (minimum inhibitory concentration $(\mathrm{MIC})=48.89 \mu \mathrm{M}$ ) against Mycobacterium abscessus (ATCC 19977), an $O$-galactosyde $(\mathrm{MIC}=31.76 \mu \mathrm{M}$ ) against Mycobacterium massiliense (ATCC 48898) and a sulfonate (MIC $=88.64 \mu \mathrm{M}$ ) against Mycobacterium fortuitum (ATCC 6841). They can form biofilms, and the infection progression is challenging to control due to multi-drug resistance profiles against diverse antibiotics. In conclusion, the above-mentioned compounds represent starting points in the search of bioactive molecules against mycobacteria with low cytotoxicity and better pharmacological profiles.
\end{abstract}

Keywords: eugenol, rapid growing mycobacteria, 1,2,3-triazoles, mycobacterium

\section{Introduction}

Increasing bacterial resistance has been an emerging problem that can be correlated with the decline of investment in antibiotic research by the pharmaceutical industry. New antibiotics are usually reserved for the treatment of difficulty-manageable infections and are prescribed for a few days. Therefore, they are considered unprofitable in comparison with the drugs to treat chronic diseases. ${ }^{1}$

Additionally to this scenario, the antimicrobial consumption in animal breeding has been unequivocally linked to cases of multi-drug resistance. ${ }^{2}$ Although bedaquiline was considered promising against

*e-mail: diogo.carvalho@unifal-mg.edu.br
Mycobacterium tuberculosis at its approval, ${ }^{3}$ effluxmediated bedaquiline resistance has already been identified in clinical management. ${ }^{4}$

Rapid growing mycobacteria (RGM) can form biofilms drastically affecting immunocompromised hosts, and the infection progression are challenging to control due to multi-drug resistance profiles against different antibiotics, ${ }^{5}$ such as clarithromycin, imipenem, ${ }^{6}$ rifampicin, isoniazid, ethambutol, pyrazinamide, ${ }^{7}$ cefoxitin, and doxycycline. ${ }^{8}$ Mycobacterium fortuitum is mainly present in skin, soft tissue and catheter associated infections, ${ }^{9}$ while Mycobacterium abscessus noticeably accounts for pulmonary infections ${ }^{10}$ and Mycobacterium massiliense for post-surgical ones. ${ }^{11}$ Considering the reduced introduction of novel antibiotics in the market and the increasing resistance to the commonly used in mycobacterial infections, the urge 
for new antimycobacterial agents is a reality. Eugenol, a natural phenylpropanoid, is known to display a diverse group of biological activities including antifungal,,${ }^{12}$ antiviral, ${ }^{13}$ anticancer, ${ }^{14}$ leishmanicidal ${ }^{15}$ and antimycobacterial activity. ${ }^{16}$ Concerning the interest in mycobacteria growth inhibition, the 1,2,3-triazole ring is an important heterocycle in medicinal chemistry and is present in compounds with prominent activity against $M$. tuberculosis strains, such as MDR-TB (multi-drug-resistant tuberculosis) and DR-TB (drug-resistant tuberculosis). ${ }^{17-20}$ Despite the lower affinity of the 1,2,3-triazole ring when compared with its congeners, imidazole and 1,2,4-triazole, upon cytochromes P450 (CYPs), this moiety is still capable of a water-bridged connection upon the $\mathrm{Fe}^{\mathrm{III}}$ of heme associated with a type II optical spectrum. ${ }^{21}$ The water participation in such coordination style is also verified for the binding of azole antifungals onto mycobacterial enzymes CYP121 and CYP51. ${ }^{22,23}$ Even though CYP121 is restricted to M. tuberculosis and essential for its viability, ${ }^{24}$ other important CYPs including CYP144 and CYP125 are present in rapid growing mycobacteria showing affinity for the azoles as well. CYP125 is required in the invasion process of macrophages by a mycobacterium. ${ }^{25}$ With these facts in mind, this work aimed to synthesize novel eugenol-derived 1,2,3-triazoles and evaluate their cytotoxic profiles and antimycobacterial activity (Figure 1).

\section{Results and Discussion}

\section{Chemistry}

Different functional groups were attached to the hydroxyl group of the eugenol phenol group to verify the influence of steric, electronic and solubility effects on activity and toxicity. Sixteen compounds were obtained in moderate to good yields (34-92\%) and characterized by nuclear magnetic resonance (NMR) spectrometry, infrared (IR) spectroscopy, and high-resolution mass spectrometry (HRMS). The key intermediate TS6 was furnished by adopting a six-step linear synthetic route starting with a silylation reaction to protect the phenolic hydroxyl group followed by hydroborationoxidation of the alkene, mesylation and azidation reactions (Scheme 1). TS1 was successfully obtained in $87 \%$ as a yellow oil by employing the silylating agent triisopropylsilyl chloride under microwave irradiation. ${ }^{26,27}$ In the ${ }^{1} \mathrm{H}$ NMR spectrum, the hydrogens from the protecting group are represented by a multiplet and duplet at $\delta$ 1.31-1.19 and $1.11 \mathrm{ppm}$, respectively. Borane addition to TS1 followed by alkaline oxidation led to the primary alcohol TS2 in $80 \% .^{28}$ The hydroxyl group is confirmed in the IR spectrum by the $-\mathrm{OH}$ stretch band noticed at $3350 \mathrm{~cm}^{-1}$ and the singlet at $\delta 1.65$ ppm in ${ }^{1} \mathrm{H}$ NMR spectrum. By a reaction of TS2 with mesyl chloride, ${ }^{29,30}$ the nucleophilic attack of sodium azide was further favored furnishing the desired alkyl azide TS4. ${ }^{31}$ The substantial withdrawing effect of the sulfonate ester in TS3 is illustrated by the triplet at $\delta 4.20 \mathrm{ppm}$ in ${ }^{1} \mathrm{H}$ spectrum that corresponds to $-\mathrm{CH}_{2} \mathrm{SO}_{2} \mathrm{Me}$ from the alkyl chain.

Intermediate TS4 was readily applied for the cycloaddition reaction promoted by copper with phenylacetylene. ${ }^{32}$ A singlet at $\delta 7.70 \mathrm{ppm}$ in the ${ }^{1} \mathrm{H}$ spectrum of TS5 is attributed to the hydrogen from the triazole ring. To perform the deprotection of the phenolic group from eugenol, a practical protocol with tetrabutylammonium fluoride (TBAF) was considered. ${ }^{33} \mathrm{~A}$ stretch band at $3521 \mathrm{~cm}^{-1}$ in the IR spectrum, the absence

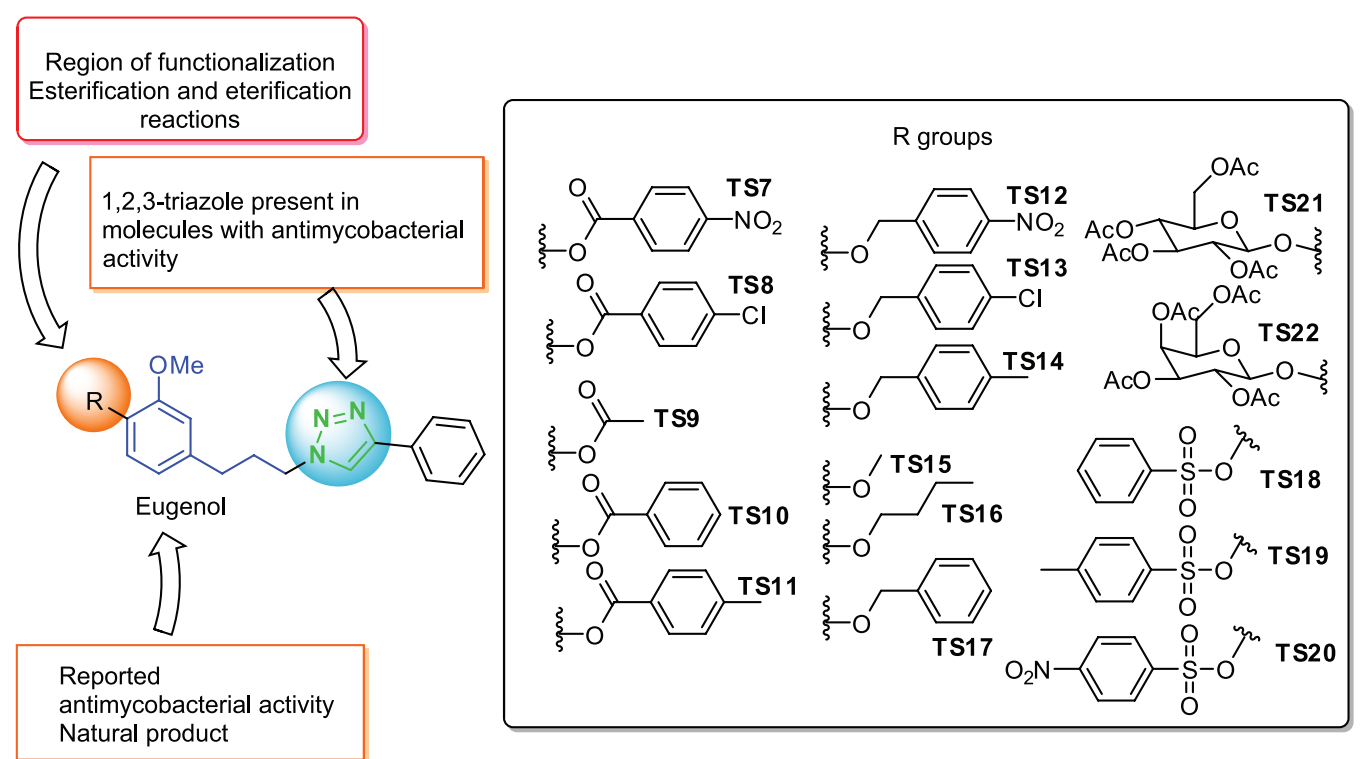

Figure 1. Eugenol-derived 1,2,3-triazoles. 


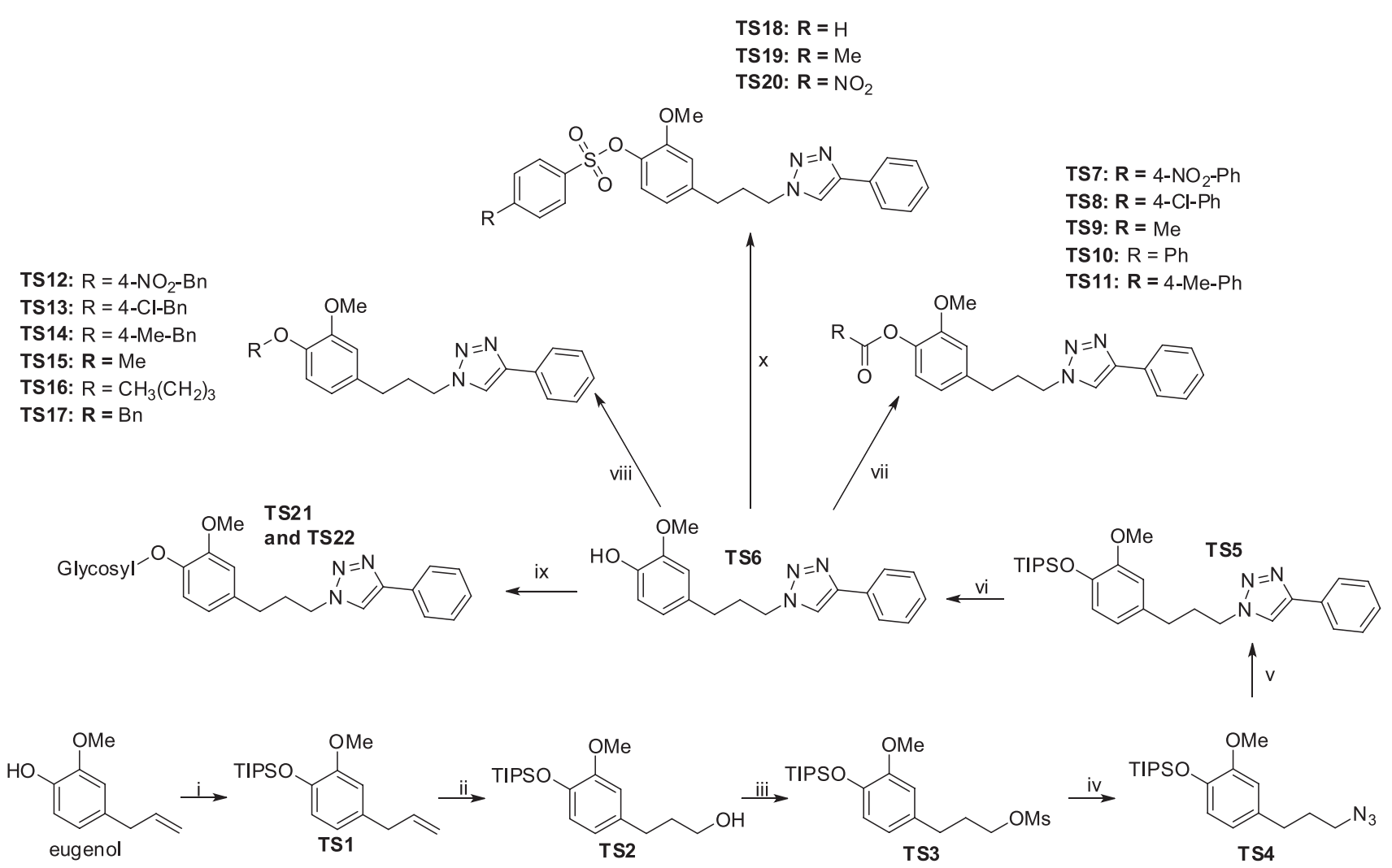

Scheme 1. The employed synthetic route. Reagents and conditions: (i) TIPSCl, imidazole, MW, 8 min, $87 \%$; (ii) $\mathrm{BH}_{3} \cdot \mathrm{SMe}_{2}$, THF, $0{ }^{\circ} \mathrm{C}$-r.t., followed by $\mathrm{NaOH}, \mathrm{H}_{2} \mathrm{O}_{2}, 0{ }^{\circ} \mathrm{C}$-r.t., $80 \%$; (iii) $\mathrm{MsCl}, \mathrm{Et}_{3} \mathrm{~N}$, DCM, $0{ }^{\circ} \mathrm{C}$-r.t., $90 \%$; (iv) $\mathrm{NaN}_{3}$, DMF, $80{ }^{\circ} \mathrm{C}$; (v) phenylacetylene, sodium ascorbate, copper acetate, DCM: $\mathrm{H}_{2} \mathrm{O}$ 1:1, r.t., $96 \%$; (vi) TBAF, THF, $0{ }^{\circ} \mathrm{C}, 20 \mathrm{~min}, 85 \%$; (vii) acetyl chloride or benzoyl chloride, pyridine, $\mathrm{DCM}, 0{ }^{\circ} \mathrm{C}-$ r.t., except for $\mathbf{T S 1 0}\left(\mathrm{Bz}_{2} \mathrm{O}\right.$, $\mathrm{Et}_{3} \mathrm{~N}$, DCM, 4-DMAP, r.t.) and TS11 (EDAC, 4-DMAP, DCM, $p$-toluic acid, r.t.), 40-92\%; (viii) respective alkyl halide or benzyl halide, $\mathrm{K}_{2} \mathrm{CO}_{3}, \mathrm{TBAB}$, $\mathrm{H}_{2} \mathrm{O}$, r.t., 37-61\%; (ix) peracetylated glycosyl bromide or peracetylated galactosyl bromide, TBAB, $\mathrm{CHCl}_{3}, \mathrm{~K}_{2} \mathrm{CO}_{3} 10 \%$ m/v, r.t., $34-35 \%$; $(x)$ respective benzenesulfonyl chloride, THF: $\mathrm{H}_{2} \mathrm{O}, \mathrm{K}_{2} \mathrm{CO}_{3} 10 \% \mathrm{~m} / \mathrm{m}, 0{ }^{\circ} \mathrm{C}$-r.t., $52-90 \%$.

of signals below $\delta 1.50 \mathrm{ppm}$ for the protecting group hydrogens and the singlet at $\delta 5.57 \mathrm{ppm}$ related to the phenolic hydrogen confirm the identity of TS6.

For the synthesis of esters TS7-TS11, the yield ranged from 40 to $92 \%$. Acyl chlorides, benzoic anhydride, and $p$-toluic acid were employed according to the general procedures described by Kieć-Kononowicz et al., ${ }^{34}$ Keraani et al. ${ }^{35}$ and $\mathrm{Pu}$ et al. ${ }^{36}$ In their IR spectra, the ester function is confirmed by the band stretch of $\mathrm{C}=\mathrm{O}$ at 1760 (TS11), 1730 (TS10), 1760 (TS9), 1736 (TS8) and $1736 \mathrm{~cm}^{-1}$ (TS7).

The ethers TS12-TS17 were synthesized in polar solvents with tetrabutylammonium bromide (TBAB, yields $37-61 \%) .{ }^{37}$ In their IR spectra, C-O stretch from methoxyl/ ether group is related to bands at $1263-1223 \mathrm{~cm}^{-1}$. Singlets at $\delta 5.18,5.07,5.08$ and $5.12 \mathrm{ppm}$ are associated with the benzylic hydrogens as expected.

Concluding the library of synthesized compounds, sulfonate esters TS18-TS20 (yields 52-90\%) and glycosides TS21 (yield 34\%) and TS22 (yield 35\%) were accomplished by adopting the protocols of Lei et al., ${ }^{38}$ Conchie et al. ${ }^{39}$ and Zhu et al.,${ }^{40}$ respectively. Two bands at 1364-1348 and 1179-1171 $\mathrm{cm}^{-1}$ for each sulfonate ester refer to $\mathrm{S}=\mathrm{O}$ stretch of the functional group. In the IR spectra of the glycosides, two strong bands at 1738 and $1743 \mathrm{~cm}^{-1}$ are associated with the $\mathrm{C}=\mathrm{O}$ stretch of the acetyls. Complementary, their ${ }^{13} \mathrm{C}$ NMR spectra present signals at $\delta$ 170.6, 170.3, 169.4 and 169.4 for TS21 and $\delta 170.6$, 170.3, 169.4 and $169.42 \mathrm{ppm}$ for TS22 that are attributed to the carbonylic carbons. For the anomeric configuration in TS22, the coupling constant $J 8.0 \mathrm{~Hz}$ in its ${ }^{1} \mathrm{H}$ NMR spectrum is conclusive of the diaxial coupling associated with a $\beta$ configuration. ${ }^{41}$

\section{Antimycobacterial activity}

To assess the compounds' potential antimycobacterial properties, a microdilution assay was employed as the standard method, including M. abscessus (ATCC 19977), M. massiliense (ATCC 48898), and M. fortuitum (ATCC 6841).

Considering the minimum inhibitory concentration (MIC) breakpoints recommended by the Clinical and Laboratory Standards Institute (CLSI) for RGM, ${ }^{42}$ 
MICs of sulfamethoxazole $(\mathrm{SMZ}) \leq 150$ and $\geq 300 \mu \mathrm{M}$ refer to susceptible and resistant strains, respectively. For clarithromycin (CLR), susceptible, intermediate and resistant strains relate to MICs $\leq 2.7,5.4$, and $\geq 10.7 \mu \mathrm{M}$, respectively. ${ }^{42}$ Therefore, among the tested strains, M. fortuitum is resistant to SMZ and CLR, and M. abscessus to CLR.

As shown in Table 1, the best growth inhibition properties from the microdilution assay against M. abscessus (ATCC 19977) were observed for TS22 $(\mathrm{MIC}=254.07 \mu \mathrm{M})$, TS16 $(\mathrm{MIC}=222.30 \mu \mathrm{M})$, TS7 $(170.39 \mu \mathrm{M})$, and TS17 $(\mathrm{MIC}=48.89 \mu \mathrm{M})$ regarding $\mathrm{MIC}=21.39$ and $31.59 \mu \mathrm{M}$ of clarithromycin and sulfamethoxazole, respectively.

Table 1. Antimycobacterial activity of the synthesized compounds

\begin{tabular}{lccc}
\hline \multirow{2}{*}{ Compound } & \multicolumn{3}{c}{ MIC / $\mu \mathrm{M}$} \\
\cline { 2 - 4 } TS5 & M. abscessus & M. massiliense & M. fortuitum \\
TS6 & 671.03 & 671.03 & 1342.07 \\
TS7 & N.A. & N.A. & N.A. \\
TS8 & 17039 & 681.57 & 681.57 \\
TS9 & N.A. & N.A. & N.A. \\
TS10 & N.A. & N.A. & N.A. \\
TS11 & 1571.95 & 1571.95 & 196.49 \\
TS12 & N.A. & N.A. & N.A. \\
TS13 & N.A. & N.A. & N.A. \\
TS14 & N.A. & N.A. & N.A. \\
TS15 & N.A. & N.A. & N.A. \\
TS16 & N.A. & N.A. & N.A. \\
TS17 & 222.30 & 222.30 & 222.30 \\
TS18 & 48.89 & 782.23 & 391.11 \\
TS19 & 709.12 & 354.56 & 88.64 \\
TS20 & N.A. & N.A. & N.A. \\
TS21 & N.A. & N.A. & N.A. \\
TS22 & N.A. & N.A. & N.A. \\
CLR & 254.07 & 31.76 & 127.03 \\
SMZ & 21.39 & 1.34 & 42.78 \\
\hline MIC: & 31.59 & 126.34 & 505.37 \\
\hline
\end{tabular}

MIC: minimum inhibitory concentration; N.A.: no activity at the tested concentrations; CLR: clarithromycin; SMZ: sulfamethoxazole.

In general, absence of activity or its decreasing was associated with the compounds bearing a fourth para substituted aromatic ring with electron-withdrawing groups $\left(-\mathrm{NO}_{2}\right.$ and $\left.-\mathrm{Cl}\right)$ or an electron-donating group $\left(-\mathrm{CH}_{3}\right)$. While the key-intermediate TS6 bearing no substituent at the hydroxyl group was not active at the tested range, its silylated precursor, TS5, showed some inhibition. For the M. massiliense inhibition, TS16 $(\mathrm{MIC}=222.30 \mu \mathrm{M})$ and TS22 $(\mathrm{MIC}=31.76 \mu \mathrm{M})$ showed relevant activities even better than sulfamethoxazole for the glycoside. The presence of a glycosyl unity in TS22 apparently is an interesting region to be maintained for further modifications. Although TS22 and TS21 are both glycosides, the galacto-configuration of TS22 seemed to consistently imply in activity for all the tested strains despite the absence on inhibition by TS21. Against $M$. fortuitum, TS16 $($ MIC $=222.30 \mu \mathrm{M})$, TS10 $($ MIC $=196.49 \mu \mathrm{M})$, TS22 $($ MIC $=127.03 \mu \mathrm{M})$ and TS18 $($ MIC $=88.64 \mu \mathrm{M})$ displayed the best results mainly when confronted with the SMZ MIC resistant-type of $505.37 \mu \mathrm{M}$.

Considering the susceptibility of the same mycobacteria strains comprised in our study to available drugs assayed by the same method (CLSI M07-A10, 2015), ${ }^{42}$ an interesting discussion can be made. Referring to the literature, the MIC of TS17 $(48.89 \mu \mathrm{M})$ against M. abscessus is noticeably inferior to what is observed for trimethoprim $(55.11 \mu \mathrm{M})$, isoniazid (> 1866.68 $\mu \mathrm{M})$, dapsone $(257.75 \mu \mathrm{M})$, tigecycline $(218.56 \mu \mathrm{M})$, meropenem $(166.90 \mu \mathrm{M})$, doxycycline $(72 \mu \mathrm{M})$, cefoxitin $(74.86 \mu \mathrm{M})$, cefepime $(133.18 \mu \mathrm{M})$ and ethambutol $(156.62 \mu \mathrm{M}))^{43,44}$ Against M. massiliense, the MIC of $\operatorname{TS22}(31.76 \mu \mathrm{M})$ is only favorable if considered with sulfamethoxazole $(252.68 \mu \mathrm{M})$ and clarithromycin $\left(42.78 \mu \mathrm{M}\right.$, resistant strain). ${ }^{43,45}$ For M. fortuitum, TS18 $(\mathrm{MIC}=88.64 \mu \mathrm{M})$ can be highlighted over sulfamethoxazole $(126.34 \mu \mathrm{M})$ and trimethoprim $(881.79 \mu \mathrm{M})$, separately. ${ }^{43}$

The parameters listed on Table 2 were obtained via the SwissADME web tool. ${ }^{46}$ Among the eugenol-derived 1,2,3-triazoles, five (TS5, TS8, TS13, TS21, and TS22) display a certain degree of violation (Table 2) for the Lipinski's rule $(\mathrm{M} \log \mathrm{P} \leq 4.15$, molecular mass $<500 \mathrm{Da}$, hydrogen bond donor and acceptor groups $\leq 5$ and $\leq 10$, respectively). ${ }^{47}$ Only TS21 and TS22 violate more than one rule (molecular masses and hydrogen bond acceptor number). The commercial drug clarithromycin is not in accordance with the same rules as well, a fact that does not exclude TS22 for a potential candidate.

\section{Cytotoxicity assay}

The cytotoxicity of each compound to Vero cells (kidney cells of African green monkey) was evaluated. Comparing the compounds in terms of cytotoxicity (Table 3), TS20 was the most toxic to Vero cells. Keeping the hydroxyl group without modifications in TS6 lessened the cytotoxicity to the same cells apart getting no activity against the considered mycobacteria strains. The ether TS17 exhibited high toxicity to M. abscessus with a selectivity index equal to 2.40 despite the other compounds. On the other hand, for M. massiliense and M. fortuitum, TS22 was highlighted to be the most toxic compound among all to mycobacteria, with a selectivity index of 7.16 and 1.79 , respectively. 
Table 2. Drug-likeness and important parameters

\begin{tabular}{|c|c|c|c|c|c|}
\hline \multirow[b]{2}{*}{ Compound } & \multicolumn{5}{|c|}{ Descriptor } \\
\hline & $\begin{array}{c}\mathrm{MM} / \\
\left(\mathrm{g} \mathrm{moL}^{-1}\right)\end{array}$ & $\begin{array}{l}\log \mathrm{P}_{\mathrm{o} / \mathrm{w}}{ }^{\mathrm{a}} \\
(\mathrm{M} \log \mathrm{P})\end{array}$ & $\mathrm{H}$ donor & $\mathrm{H}$ acceptor & $\begin{array}{c}\text { Lipinski's } \\
\text { violation }\end{array}$ \\
\hline TS5 & 465.70 & 4.35 & 0 & 4 & 1 \\
\hline TS6 & 309.36 & 2.41 & 1 & 4 & 0 \\
\hline TS7 & 458.47 & 3.04 & 0 & 7 & 0 \\
\hline TS8 & 447.91 & 4.40 & 0 & 5 & 1 \\
\hline TS9 & 351.40 & 2.80 & 0 & 5 & 0 \\
\hline TS10 & 413.47 & 3.92 & 0 & 5 & 0 \\
\hline TS11 & 427.50 & 4.13 & 0 & 5 & 0 \\
\hline TS12 & 444.48 & 2.81 & 0 & 6 & 0 \\
\hline TS13 & 433.93 & 4.20 & 0 & 4 & 1 \\
\hline TS14 & 413.51 & 3.93 & 0 & 4 & 0 \\
\hline TS15 & 323.39 & 2.64 & 0 & 4 & 0 \\
\hline TS16 & 365.47 & 3.31 & 0 & 4 & 0 \\
\hline TS17 & 399.48 & 3.73 & 0 & 4 & 0 \\
\hline TS18 & 449.52 & 3.66 & 0 & 6 & 0 \\
\hline TS19 & 463.55 & 3.87 & 0 & 6 & 0 \\
\hline TS20 & 494.52 & 2.81 & 0 & 8 & 0 \\
\hline TS21 & 639.65 & 1.72 & 0 & 13 & 2 \\
\hline TS22 & 639.65 & 1.72 & 0 & 13 & 2 \\
\hline CLR & 747.95 & -0.54 & 4 & 14 & 2 \\
\hline SMZ & 253.28 & -0.15 & 2 & 4 & 0 \\
\hline
\end{tabular}

aipophilicity descriptor. MM: molecular mass; $\log \mathrm{P}_{\mathrm{o} / \mathrm{w}}$ : octanol water partition coefficient; CLR: clarithromycin; SMZ: sulfamethoxazole.

\section{Conclusions}

All in all, sixteen novel eugenol-derived 1,2,3-triazoles were obtained in moderate to good yields. The best antimycobacterial activity against RGM were observed for TS17 $(\mathrm{MIC}=48.89 \mu \mathrm{M})$ against $M$. abscessus (ATCC 19977), TS22 (MIC = 31.76 $\mu \mathrm{M}$ ) against M. massiliense (ATCC 48898), and TS18 $(\mathrm{MIC}=88.64 \mu \mathrm{M})$ against $M$. fortuitum (ATCC 6841). Therefore, our research group considers these compounds good prototypes in the search of bioactive molecules against rapid-growing mycobacteria of better cytotoxicity and pharmacological profiles.

\section{Experimental}

\section{General information}

Reagents and solvents employed for the reactions were reagent grade and used as purchased. All the reactions were monitored via thin layer chromatography (TLC) with a uniform layer of silica gel (Macherey-Nagel, DC-Fertigfolien ALUGRAM® Xtra Sil G/UV254). Column chromatography was performed using silica gel 60, 70-230 mesh Sorbline. ${ }^{1} \mathrm{H}$ and ${ }^{13} \mathrm{C}$ spectra were recorded on a Bruker $\mathrm{AC}-300$ spectrometer at 300 and $75 \mathrm{MHz}$, respectively, using $\mathrm{CDCl}_{3}$ (deuterated chloroform)

Table 3. Cytotoxicity to Vero cells and selectivity index

\begin{tabular}{|c|c|c|c|c|}
\hline \multirow{2}{*}{ Compound } & \multirow{2}{*}{$\mathrm{CC}_{50} / \mu \mathrm{M}$} & \multicolumn{3}{|c|}{ Selectivity index } \\
\hline & & M. abscessus & M. massiliense & M. fortuitum \\
\hline TS5 & $62.16 \pm 4.47$ & 0.09 & 0.09 & 0.05 \\
\hline TS6 & $275.95 \pm 23.11$ & - & - & - \\
\hline TS7 & $114.22 \pm 4.65$ & 0.67 & 0.17 & 0.17 \\
\hline TS8 & $114.13 \pm 11.14$ & - & - & - \\
\hline TS9 & $105.55 \pm 23.97$ & - & - & - \\
\hline TS10 & $78.63 \pm 2.06$ & 0.05 & 0.05 & 0.40 \\
\hline TS11 & $68.91 \pm 1.22$ & - & - & - \\
\hline TS12 & $59.48 \pm 0.38$ & - & - & - \\
\hline TS13 & $67.13 \pm 0.62$ & - & - & - \\
\hline TS14 & $50.69 \pm 5.80$ & - & - & - \\
\hline TS15 & $86.05 \pm 12.09$ & - & - & - \\
\hline TS16 & $74.34 \pm 5.86$ & 0.33 & 0.33 & 0.33 \\
\hline TS17 & $117.42 \pm 40.90$ & 2.40 & 0.15 & 0.30 \\
\hline TS18 & $52.86 \pm 1.00$ & 0.07 & 0.15 & 0.60 \\
\hline TS19 & $42.13 \pm 2.69$ & - & - & - \\
\hline TS20 & $37.84 \pm 2.34$ & - & - & - \\
\hline TS21 & $61.36 \pm 15.44$ & - & - & - \\
\hline TS22 & $227.46 \pm 21.62$ & 0.90 & 7.16 & 1.79 \\
\hline
\end{tabular}

$\mathrm{CC}_{50}$ : cytotoxic concentration for 50\%; - : selectivity index was not calculated (no activity against the tested RGM strains). The best results are highlighted. 
as solvent and TMS (tetramethylsilane) as the internal standard. IR data were recorded with a Thermo Scientific Nicolet-iS50 spectrometer with attenuated total reflectance (ATR) and the values are described in wave numbers $\left(\bar{v}_{\max }\right.$, in $\mathrm{cm}^{-1}$ ).

High-resolution mass spectra were obtained with a Bruker Daltonics micrOTOF QII/ESI-TOF (electrospray ionization time-of-flight). For the reactions carried out under microwave (MW) irradiation, a conventional microwave was used (LG MS3048G, output power $800 \mathrm{~W}$, IEC60705). Melting point data was obtained with a Bücher $535\left(0-300{ }^{\circ} \mathrm{C}\right)$ instrument, calibrated with vanillin P.A. Merck $^{\circledR}$.

\section{Synthetic procedures}

[2-Methoxy-4-(prop-2-en-1-yl)phenoxy]tris(propan-2-yl) silane (TS1)

A mixture of eugenol (1 equiv., $3.2 \mathrm{mmol}$ ), TIPSCl (1.5 equiv., $4.8 \mathrm{mmol}$ ) and imidazole (3 equiv., $9.6 \mathrm{mmol})$ in a round-bottom flask was subjected to microwave irradiation in turns of $20 \mathrm{~s}$ each until the total of $8 \mathrm{~min}$. The mixture was washed with EtOAc $(4 \mathrm{~mL})$. The combined organic layers were quenched with $\mathrm{NaHCO}_{3}$, dried over $\mathrm{MgSO}_{4}$ and evaporated under reduced pressure. The crude product was purified by silica gel column chromatography (hexane/EtOAc 9.8:0.2) to give TS1 as a light yellow oil, yield $87 \%$, IR (ATR) $\bar{v}_{\max } / \mathrm{cm}^{-1} 3078,3056,3037,2943$, 2892, 2865, 1638, 1605, 1584, 1510, 1463, 1282, 1230, 912, 881; ' $\mathrm{H}$ NMR $\left(300 \mathrm{MHz}, \mathrm{CDCl}_{3}\right) \delta 6.81(\mathrm{~d}, 1 \mathrm{H}$, $J 8.0 \mathrm{~Hz}, \mathrm{Ar}-\mathrm{H}), 6.68(\mathrm{~d}, 1 \mathrm{H}, J 2.1 \mathrm{~Hz}, \mathrm{Ar}-\mathrm{H}), 6.63(\mathrm{dd}$, $1 \mathrm{H}, J$ 8.0, $2.1 \mathrm{~Hz}, \mathrm{Ar}-\mathrm{H}), 6.05-5.89\left(\mathrm{~m}, 1 \mathrm{H}, \mathrm{CH}_{2}-\mathrm{C} \underline{\mathrm{H}}=\mathrm{CH}_{2}\right.$ ), 5.11-5.06 (m, $\left.1 \mathrm{H}, \mathrm{CH}_{2}-\mathrm{CH}=\mathrm{C}_{2}\right), 5.04$ (t, $1 \mathrm{H}, J 1.4 \mathrm{~Hz}$, $\left.\mathrm{CH}_{2}-\mathrm{CH}=\mathrm{CH}_{2}\right), 3.80\left(\mathrm{~s}, 3 \mathrm{H}, \mathrm{OCH}_{3}\right), 3.33(\mathrm{~d}, 2 \mathrm{H}, J 6.6 \mathrm{~Hz}$, $\mathrm{CH}_{2}$ ), 1.31-1.19 (m, 3H, CH-Si), 1.11 (d, $18 \mathrm{H}, J 6.8 \mathrm{~Hz}$, $\left.\mathrm{CH}_{3}\right) ;{ }^{13} \mathrm{C}$ NMR $\left(75 \mathrm{MHz}, \mathrm{CDCl}_{3}\right) \delta 150.7,143.8,137.9$, 133.0, 120.6, 120.2, 115.4, 112.7, 55.5, 39.9, 17.9, 12.9 .

\section{3-(3-Methoxy-4-\{[tris(propan-2-yl)silyl]oxy\}phenyl)propan- 1-ol (TS2)}

To the round-bottom flask containing TS1 (1 equiv., $1.88 \mathrm{mmol}$ ) and tetrahydrofuran (THF, $11 \mathrm{~mL}$ ), borane dimethyl sulfide (2 equiv., $3.76 \mathrm{mmol}$ ) was added dropwise under argon atmosphere. The mixture was stirred for $1 \mathrm{~h}$ at $0{ }^{\circ} \mathrm{C}$ and $1 \mathrm{~h} 30 \mathrm{~min}$ at room temperature. Then, $1 \mathrm{M} \mathrm{NaOH}$ (2.5 equiv., $4.7 \mathrm{~mL}$ ) was cautiously added to this flask at $0{ }^{\circ} \mathrm{C}$ followed by $30 \% \mathrm{H}_{2} \mathrm{O}_{2}(4.7 \mathrm{~mL})$. The mixture was stirred at $0{ }^{\circ} \mathrm{C}$ for $1 \mathrm{~h}$ and at room temperature for $2 \mathrm{~h}$. After, $\mathrm{Et}_{2} \mathrm{O}$ was added and the combined organic layers were washed with a $\mathrm{NaCl}$ saturated solution, dried over $\mathrm{MgSO}_{4}$ and evaporated under reduced pressure. The crude product was purified by silica gel column chromatography (hexane/EtOAc 6:4) to give TS2 as a yellow oil, yield 80\%, IR (ATR) $\bar{v}_{\max } / \mathrm{cm}^{-1} 3350,3035,2941,2892,2865,1606$, $1583,1513,1463,1283,1231 ;{ }^{1} \mathrm{H}$ NMR $\left(300 \mathrm{MHz}, \mathrm{CDCl}_{3}\right)$ $\delta 6.80(\mathrm{~d}, 1 \mathrm{H}, J 8.0 \mathrm{~Hz}, \mathrm{Ar}-\mathrm{H}), 6.70(\mathrm{~d}, 1 \mathrm{H}, J 2.1 \mathrm{~Hz}$, Ar-H), 6.64 (dd, 1H, J 8.0, $2.1 \mathrm{~Hz}$, Ar-H), 3.81 (s, 3H, $\mathrm{OCH}_{3}$ ), 3.67 (t, $\left.2 \mathrm{H}, J 6.4 \mathrm{~Hz}, \mathrm{C}_{2}-\mathrm{OH}\right), 2.70-2.61$ (t, $2 \mathrm{H}$, $\left.\mathrm{CH}_{2}\right), 1.94-1.83\left(\mathrm{~m}, 2 \mathrm{H}, \mathrm{CH}_{2}\right), 1.65(\mathrm{~s}, 1 \mathrm{H}, \mathrm{OH}) 1.31-1.20$ (m, 3H, CH-Si), 1.11 (d, $\left.18 \mathrm{H}, \mathrm{CH}_{3}\right) ;{ }^{13} \mathrm{C}$ NMR $(75 \mathrm{MHz}$, $\left.\mathrm{CDCl}_{3}\right) \delta 150.7,143.6,134.9,120.3,120.2,112.5,62.3$, $55.5,34.3,31.8,17.9,12.9$.

[4-(3-Azidopropyl)-2-methoxyphenoxy]tris(propan-2-yl) silane (TS3)

To the round-bottom flask containing TS2 (1 equiv., $1.5 \mathrm{mmol}$ ) and dry dichloromethane (DCM, $10 \mathrm{~mL}$ ) at $0{ }^{\circ} \mathrm{C}$ under argon atmosphere, it was added triethylamine (3 equiv., $4.5 \mathrm{mmol}$ ) and methanesulfonyl chloride (2.5 equiv., $3.75 \mathrm{mmol}$ ) dropwise. The mixture was stirred at room temperature for $4 \mathrm{~h}$ and then washed with $1 \mathrm{M} \mathrm{HCl}$, $\mathrm{NaHCO}_{3}$, and a $\mathrm{NaCl}$ saturated solution. After multiple extractions with minimal quantities of DCM, the organic layers were combined, dried over $\mathrm{MgSO}_{4}$ and evaporated under reduced pressure. The crude product was purified by silica gel column chromatography (DCM) to give TS3 as a yellow oil, yield 90\%, IR (ATR) $\bar{v}_{\max } / \mathrm{cm}^{-1} 3031,2942$, 2892, 2865, 1605, 1583, 1514, 1464, 1351, 1273, 1232, $1172 ;{ }^{1} \mathrm{H}$ NMR $\left(300 \mathrm{MHz}, \mathrm{CDCl}_{3}\right) \delta 6.79(\mathrm{~d}, 1 \mathrm{H}, J 8.0 \mathrm{~Hz}$, Ar-H), 6.66 (d, 1H, J 2.1 Hz, Ar-H), 6.60 (dd, 1H, J 8.0, $2.1 \mathrm{~Hz}, \mathrm{Ar}-\mathrm{H}), 4.20$ (t, $\left.2 \mathrm{H}, J 6.3 \mathrm{~Hz}, \mathrm{C}_{2} \mathrm{OSO}_{2} \mathrm{CH}_{3}\right), 3.78$ (s, $\left.3 \mathrm{H}, \mathrm{OCH}_{3}\right), 2.98\left(\mathrm{~s}, 3 \mathrm{H}, \mathrm{CH}_{2} \mathrm{OSO}_{2} \mathrm{C}_{3}\right), 2.67(\mathrm{t}, 2 \mathrm{H}$, J 7.4 Hz, $\left.\mathrm{CH}_{2}\right), 2.10-1.98\left(\mathrm{~m}, 2 \mathrm{H}, \mathrm{CH}_{2}\right), 1.29-1.16(\mathrm{~m}, 3 \mathrm{H}$, $\mathrm{C} \underline{\mathrm{H}}-\mathrm{Si}), 1.08$ (d, $\left.18 \mathrm{H}, \mathrm{CH}_{3}\right) ;{ }^{13} \mathrm{C} \mathrm{NMR}\left(75 \mathrm{MHz}, \mathrm{CDCl}_{3}\right)$ $\delta 150.8,143.9,133.3,120.4,112.5,69.2,55.5,37.3,31.1$, $30.8,17.9,12.9$.

3-(3-Methoxy-4-\{[tris(propan-2-yl)silyl]oxy\}phenyl)propyl methanesulfonate (TS4)

A mixture of sodium azide (2 equiv., $5.08 \mathrm{mmol}$ ) and TS3 (1 equiv., $2.54 \mathrm{mmol}$ ) in dimethylformamide (DMF, $10 \mathrm{~mL})$ was stirred for $2 \mathrm{~h}$ at $80^{\circ} \mathrm{C}$. After, EtOAc $(10 \mathrm{~mL})$ was added, and the mixture was washed with distilled water $(4 \times 5 \mathrm{~mL})$ to remove DMF and traces of $\mathrm{NaN}_{3}$. The organic layer was dried over $\mathrm{MgSO}_{4}$ and evaporated under reduced pressure to give pure TS4 without further purification. TS4 was readily used in the next synthetic step.

1-[3-(3-Methoxy-4-\{[tris(propan-2-yl)silyl]oxy\}phenyl) propyl]-4-phenyl-1 $H$-1,2,3-triazole (TS5)

To the round-bottom flask containing $5 \mathrm{~mL}$ of a sodium ascorbate solution $(5 \mathrm{~mL}$ of distilled water, $0.16 \mathrm{mmol}$ of 
ascorbic acid, $0.16 \mathrm{mmol}$ of sodium bicarbonate), TS4 (1 equiv., $1.13 \mathrm{mmol})$ in DCM $(5 \mathrm{~mL})$, phenylacetylene (1.1 equiv., $1.13 \mathrm{mmol})$ and copper acetate $(5 \% \mathrm{mmol}$ phenylacetylene, $0.06 \mathrm{mmol}$ ) were added in this order. The mixture was stirred overnight at room temperature. Then, $\operatorname{DCM}(10 \mathrm{~mL})$ was added, and the mixture was washed with distilled water. The organic layer was dried over $\mathrm{Na}_{2} \mathrm{SO}_{4}$ and evaporated under reduced pressure. The crude product was purified by silica gel column chromatography (hexane/ EtOAc 6:4) to give TS5 as a white solid, yield 96\%, m.p. 74-80 ${ }^{\circ} \mathrm{C}$; IR (ATR) $\bar{v}_{\max } / \mathrm{cm}^{-1} 3130,3056,3034,3002$, 2944, 2892, 2864, 1582, 1512, 1468; ${ }^{1} \mathrm{H}$ NMR (300 MHz, $\left.\mathrm{CDCl}_{3}\right) \delta 7.83(\mathrm{~m}, 2 \mathrm{H}, J 8.3,1.3 \mathrm{~Hz}, \mathrm{Ar}-\mathrm{H}), 7.70(\mathrm{~s}, 1 \mathrm{H}$, triazole-H), 7.46-7.39 (m, 2H, Ar-H), 7.37-7.29 (m, $1 \mathrm{H}$, Ar-H), 6.80 (d, 1H, J 8.0 Hz, Ar-H), 6.66 (d, 1H, J $2.1 \mathrm{~Hz}$, Ar-H), $6.61(\mathrm{dd}, 1 \mathrm{H}, J$ 8.0, $2.1 \mathrm{~Hz}, \mathrm{Ar}-\mathrm{H}), 4.38(\mathrm{t}, 2 \mathrm{H}$, $\left.J 7.1 \mathrm{~Hz}, \mathrm{CH}_{2}-\mathrm{N}\right), 3.78\left(\mathrm{~s}, 3 \mathrm{H}, \mathrm{OCH}_{3}\right), 2.61(\mathrm{t}, 2 \mathrm{H}, J 7.4 \mathrm{~Hz}$, $\left.\mathrm{CH}_{2}\right), 2.26\left(\mathrm{~m}, 2 \mathrm{H}, J 7.1 \mathrm{~Hz}, \mathrm{CH}_{2}\right), 1.24(\mathrm{~m}, 3 \mathrm{H}, \mathrm{CHSi})$, $1.09\left(\mathrm{~d}, 18 \mathrm{H}, \mathrm{CH}_{3}\right) ;{ }^{13} \mathrm{C} \mathrm{NMR}\left(75 \mathrm{MHz}, \mathrm{CDCl}_{3}\right) \delta 150.9$, 147.7, 144.0, 133.1, 130.6, 128.9, 128.1, 125.7, 120.4 (2C), 119.6, 112.6, 55.5, 49.5, 32.1, 31.8, 17.9, 12.9.

\section{2-Methoxy-4-[3-(4-phenyl-1H-1,2,3-triazol-1-yl)propyl] phenol (TS6)}

TBAF (1.5 equiv., $0.69 \mathrm{mmol}$ ) was added to a roundbottom flask containing TS5 (1 equiv., $0.46 \mathrm{mmol}$ ) in THF $(14 \mathrm{~mL})$ at $0{ }^{\circ} \mathrm{C}$. The mixture was stirred at this temperature for $20 \mathrm{~min}$, and after quenched with $\mathrm{NH}_{4} \mathrm{Cl}$ $(10 \mathrm{~mL})$. Multiple extractions with minimal quantities of EtOAc were performed, and the combined organic layers were dried over $\mathrm{Na}_{2} \mathrm{SO}_{4}$ and evaporated under reduced pressure. The crude product was purified by silica gel column chromatography (hexane/EtOAc 6:4) to give TS6 as a light yellow solid, yield $85 \%$, m.p. $76-80^{\circ} \mathrm{C}$; IR (ATR) $\bar{v}_{\text {max }} / \mathrm{cm}^{-1} 3521,3141,3102,3065,3030,2964,2928,2850$, $1605,1517,1461 ;{ }^{1} \mathrm{H}$ NMR $\left(300 \mathrm{MHz}, \mathrm{CDCl}_{3}\right) \delta 7.85-7.80$ $(\mathrm{m}, 2 \mathrm{H}, \mathrm{Ar}-\mathrm{H}), 7.70(\mathrm{~s}, 1 \mathrm{H}$, triazole-H), 7.49-7.25 (m, 3H, Ar-H), 6.89-6.65 (m, 3H, Ar-H), 5.57 (s, 1H, OH), 4.39 $\left(\mathrm{t}, 2 \mathrm{H}, J 7.0 \mathrm{~Hz}, \mathrm{CH}_{2} \mathrm{~N}\right), 3.86\left(\mathrm{~s}, 3 \mathrm{H}, \mathrm{OCH}_{3}\right), 2.62(\mathrm{t}, 2 \mathrm{H}$, $\left.J 7.4 \mathrm{~Hz}, \mathrm{CH}_{2}\right), 2.32-2.20\left(\mathrm{~m}, 2 \mathrm{H}, \mathrm{CH}_{2}\right) ;{ }^{13} \mathrm{C} \mathrm{NMR}(75 \mathrm{MHz}$, $\left.\mathrm{CDCl}_{3}\right) \delta 147.8,146.6,144.1,132.0,130.6,128.9,128.2$, 125.7, 121.0, 119.6, 114.4, 111.1, 55.9, 49.5, 32.2, 31.9.

\section{General synthetic procedures to obtain TS7, TS8 and TS9}

The corresponding benzoyl chloride (1.5 equiv., 0.34 mmol, TS7 (4-nitrobenzoyl chloride), TS8 (4-chlorobenzoyl chloride)) or acetyl chloride (1.5 equiv., $0.34 \mathrm{mmol}$, TS9) were added to a round-bottom flask containing TS6 (1 equiv., $0.23 \mathrm{mmol})$ in pyridine $(2 \mathrm{~mL})$ at $0{ }^{\circ} \mathrm{C}$. The mixture was stirred at room temperature for
$24 \mathrm{~h}$. After, DCM was added. The mixture was washed with cold $2 \% \mathrm{HCl}$ and then with $\mathrm{NaHCO}_{3}$. The organic layer was dried over $\mathrm{MgSO}_{4}$ and evaporated under reduced pressure. The crude products were purified by silica gel column chromatography (hexane/EtOAc 6:4) to give TS7, TS8, and TS9.

2-Methoxy-4-[3-(4-phenyl-1 H-1,2,3-triazol-1-yl)propyl] phenyl 4-nitrobenzoate (TS7)

Yellow solid, yield $41 \%$, m.p. $100-110{ }^{\circ} \mathrm{C}$; IR (ATR) $\bar{v}_{\max } / \mathrm{cm}^{-1}$ 3106, 3079, 3052, 3019, 2952, 2924, 2852, 1736, 1526, 1510, 1346; ${ }^{1} \mathrm{H}$ NMR (300 MHz, $\mathrm{CDCl}_{3}$ )

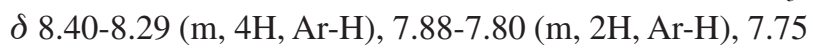
(s, 1H, triazole-H), 7.48-7.24 (m, 3H, Ar-H), 7.13-6.79 (m, 3H, Ar-H), 4.44 (t, $\left.2 \mathrm{H}, J 6.9 \mathrm{~Hz}, \mathrm{CH}_{2} \mathrm{~N}\right), 3.80(\mathrm{~s}, 3 \mathrm{H}$, $\left.\mathrm{OCH}_{3}\right), 2.71\left(\mathrm{t}, 2 \mathrm{H}, J 7.5 \mathrm{~Hz}, \mathrm{CH}_{2}\right), 2.39-2.26\left(\mathrm{~m}, 2 \mathrm{H}, \mathrm{CH}_{2}\right)$; ${ }^{13} \mathrm{C}$ NMR $\left(75 \mathrm{MHz}, \mathrm{CDCl}_{3}\right) \delta 163.0,151.0,150.8,147.9$, 139.8, 138.0, 134.9, 131.4, 130.6, 128.9, 128.2, 125.7, 123.7, 122.6, 120.6, 119.6, 112.9, 55.9, 49.5, 32.5, 31.7; HRMS (ESI-TOF) $\mathrm{m} / \mathrm{z}$ calculated for $[\mathrm{M}+\mathrm{H}]^{+}: 459.1590$, found: 459.1639 .

2-Methoxy-4-[3-(4-phenyl-1 $H$-1,2,3-triazol-1-yl)propyl] phenyl 4-chlorobenzoate (TS8)

White solid, yield 50\%, m.p. $100-116^{\circ} \mathrm{C}$; IR (ATR) $\bar{v}_{\max } / \mathrm{cm}^{-1} 3132,3077,3052,2995,2949,2852,1736,1509$, 1459; ${ }^{1} \mathrm{H}$ NMR $\left(300 \mathrm{MHz}, \mathrm{CDCl}_{3}\right) \delta 8.17-8.11(\mathrm{~m}, 2 \mathrm{H}$, Ar-H), 7.87-7.82 (m, 2H, Ar-H), $7.75(\mathrm{~s}, 1 \mathrm{H}$, triazole-H), 7.51-7.40 (m, 4H, Ar-H), 7.34 (m, 1H, J 7.3, 1.3 Hz, Ar-H), 7.07 (d, 1H, J 7.9 Hz, Ar-H), 6.83 (s, 1H, Ar-H), 6.80 (d, $1 \mathrm{H}, J 1.9 \mathrm{~Hz}, \mathrm{Ar}-\mathrm{H}), 4.44$ (t, $\left.2 \mathrm{H}, J 6.9 \mathrm{~Hz}, \mathrm{CH}_{2} \mathrm{~N}\right), 3.80$ (s, $\left.3 \mathrm{H}, \mathrm{OCH}_{3}\right), 2.70\left(\mathrm{t}, 2 \mathrm{H}, J 7.5 \mathrm{~Hz}, \mathrm{CH}_{2}\right), 2.43-2.19(\mathrm{~m}, 2 \mathrm{H}$, $\left.\mathrm{CH}_{2}\right) ;{ }^{13} \mathrm{C}$ NMR $\left(75 \mathrm{MHz}, \mathrm{CDCl}_{3}\right) \delta 164.1,151.2,147.9$, $140.0,139.3,138.2,131.7,131.5,130.6,128.9,128.2$, $127.9,125.7,122.8,120.6,119.6,112.9,56.0,49.5,32.5$, 31.7; HRMS (ESI-TOF) $\mathrm{m} / \mathrm{z}$ calculated for $[\mathrm{M}+\mathrm{H}]^{+}$: 448.1350, found: 448.1424 .

2-Methoxy-4-[3-(4-phenyl-1 H-1,2,3-triazol-1-yl)propyl] phenyl acetate (TS9)

Yellow solid, yield 40\%, m.p. $110-115{ }^{\circ} \mathrm{C}$; IR (ATR) $\bar{v}_{\max } / \mathrm{cm}^{-1}$ 3130, 3037, 2978, 2921, 2850, 1760, 1508; ${ }^{1} \mathrm{H}$ NMR $\left(300 \mathrm{MHz}, \mathrm{CDCl}_{3}\right) \delta 7.83(\mathrm{~m}, 2 \mathrm{H}, J 8.2,1.7 \mathrm{~Hz}$, Ar-H), 7.74 (s, 1H, triazole-H), 7.49-7.20 (m, 3H, Ar-H), 6.96 (d, 1H, J 7.9 Hz, Ar-H), 6.80-6.73 (m, 2H, Ar-H), 4.41 (t, $\left.2 \mathrm{H}, J 7.0 \mathrm{~Hz}, \mathrm{CH}_{2} \mathrm{~N}\right), 3.81\left(\mathrm{~s}, 3 \mathrm{H}, \mathrm{OCH}_{3}\right), 2.66(\mathrm{t}, 2 \mathrm{H}$, $\left.J 7.5 \mathrm{~Hz}, \mathrm{CH}_{2}\right), 2.34-2.23$ (m, 5H, $\left.\mathrm{CH}_{2}, \mathrm{CH}_{3}\right) ;{ }^{13} \mathrm{C} \mathrm{NMR}$ $\left(75 \mathrm{MHz}, \mathrm{CDCl}_{3}\right) \delta 169.2,151.1,147.8,139.1,138.2$, 130.6, 128.9, 128.2, 125.7, 122.8, 120.5, 119.6, 112.7, 55.9, 49.5, 32.4, 31.7, 20.7; HRMS (ESI-TOF) $\mathrm{m} / \mathrm{z}$ calculated for $[\mathrm{M}+\mathrm{H}]^{+}: 352.1583$, found: 352.1656 . 
2-Methoxy-4-[3-(4-phenyl-1H-1,2,3-triazol-1-yl)propyl] phenyl benzoate (TS10)

To a round-bottom flask containing TS6 (1 equiv., $0.26 \mathrm{mmol})$ in $\mathrm{DCM}(2 \mathrm{~mL})$ was added $\mathrm{Et}_{3} \mathrm{~N}$ (2.3 equiv., $0.59 \mathrm{mmol}$ ) followed by benzoic anhydride (2.1 equiv., $0.54 \mathrm{mmol}$ ) and 4-dimethylaminopyridine (4-DMAP, 0.1 equiv., $0.026 \mathrm{mmol})$. The mixture was stirred at room temperature for $5 \mathrm{~h}$. After, DCM $(4 \mathrm{~mL})$ was added and the mixture was washed with a saturated solution of $\mathrm{NaHCO}_{3}$. The organic layer was dried over $\mathrm{MgSO}_{4}$ and evaporated under reduced pressure. The crude product was purified by silica gel column chromatography (hexane/EtOAc 7:3) to give TS10 as a light yellow solid, yield 92\%, m.p. 75-82 ${ }^{\circ} \mathrm{C}$; IR (ATR) $\bar{v}_{\max } / \mathrm{cm}^{-1} 3075,3057,2980,2966$, 2946, 2913, 2867, 1730, 1600, 1510; ' $\mathrm{H}$ NMR $(300 \mathrm{MHz}$, $\left.\mathrm{CDCl}_{3}\right) \delta 8.25-8.18(\mathrm{~m}, 2 \mathrm{H}, \mathrm{Ar}-\mathrm{H}), 7.84(\mathrm{~m}, 2 \mathrm{H}, J 8.2$, $1.8 \mathrm{~Hz}, \mathrm{Ar}-\mathrm{H}), 7.75(\mathrm{~s}, 1 \mathrm{H}$, triazole-H), 7.66-7.59 $(\mathrm{m}, 1 \mathrm{H}$, Ar-H), 7.54-7.39 (m, 4H, Ar-H), 7.37-7.30 (m, 1H, Ar-H), 7.08 (d, 1H, J 7.9 Hz, Ar-H), 6.83 (s, 1H, Ar-H), 6.79 (d, $J 1.9 \mathrm{~Hz}, 1 \mathrm{H}, \mathrm{Ar}-\mathrm{H}), 4.42\left(\mathrm{t}, 2 \mathrm{H}, J 7.0 \mathrm{~Hz}, \mathrm{CH}_{2} \mathrm{~N}\right), 3.79$ (s, 3H, $\left.\mathrm{OCH}_{3}\right), 2.69$ (t, $2 \mathrm{H}, J 7.5 \mathrm{~Hz}, 2 \mathrm{H}, \mathrm{CH}_{2}$ ), 2.37-2.25 $\left(\mathrm{m}, 2 \mathrm{H}, \mathrm{CH}_{2}\right) ;{ }^{13} \mathrm{C} \mathrm{NMR}\left(75 \mathrm{MHz}, \mathrm{CDCl}_{3}\right) \delta 164.9,151.3$, $147.8,139.2,138.4,133.5,130.6,130.3,129.4,128.9$, $128.5,128.2,125.9,125.7,122.9,120.6,119.7,112.9$, 56.0, 49.5, 32.5, 31.7; HRMS (ESI-TOF) $\mathrm{m} / \mathrm{z}$ calculated for $[\mathrm{M}+\mathrm{H}]^{+}:$414.1739, found: 414.1815 .

2-Methoxy-4-[3-(4-phenyl-1 $H$-1,2,3-triazol-1-yl)propyl] phenyl 4-methylbenzoate (TS11)

To a round-bottom flask containing $p$-toluic acid ( 1 equiv., $0.23 \mathrm{mmol})$ in DCM $(3 \mathrm{~mL})$, TS6 (1 equiv., $0.23 \mathrm{mmol}$ ), 1-ethyl-3-(3-dimethylaminopropyl) carbodiimide (EDAC, 1.3 equiv., $0.25 \mathrm{mmol}$ ), and 4-DMAP ( 0.25 equiv., $0.06 \mathrm{mmol}$ ) were added. The mixture was stirred at room temperature for $24 \mathrm{~h}$. After, $\mathrm{NaHCO}_{3}$ (saturated solution, $4 \mathrm{~mL}$ ) was added, and extractions (3x) with minimal quantities of DCM were performed. The combined organic layers were dried over $\mathrm{MgSO}_{4}$ and evaporated under reduced pressure. The crude product was purified by silica gel column chromatography (hexane/ EtOAc 7:3) to give TS11 as a white solid, yield 60\%, m.p. 80-95 ${ }^{\circ}$ C; IR (ATR) $\bar{v}_{\max } / \mathrm{cm}^{-1} 3090,3050,3031$, 2959, 2923, 2852, 1736, 1610, 1508; ' $\mathrm{H}$ NMR (300 MHz, $\left.\mathrm{CDCl}_{3}\right) \delta 8.09(\mathrm{~d}, 2 \mathrm{H}, J 8.2 \mathrm{~Hz}, \mathrm{Ar}-\mathrm{H}), 7.87-7.81(\mathrm{~m}, 2 \mathrm{H}$, Ar-H), 7.75 (s, 1H, triazole-H), $7.43(\mathrm{t}, 2 \mathrm{H}, J 7.4 \mathrm{~Hz}$, Ar-H), 7.37-7.25 (m, 3H, Ar-H), 7.10-6.78 (m, 3H, Ar-H), $4.44\left(\mathrm{t}, 2 \mathrm{H}, J 7.0 \mathrm{~Hz}, \mathrm{CH}_{2} \mathrm{~N}\right), 3.79\left(\mathrm{~s}, 3 \mathrm{H}, \mathrm{OCH}_{3}\right), 2.70$ (t, $\left.2 \mathrm{H}, J 7.5 \mathrm{~Hz}, \mathrm{CH}_{2}\right), 2.44\left(\mathrm{~s}, 3 \mathrm{H}, \mathrm{CH}_{3}\right), 2.38-2.26(\mathrm{~m}, 2 \mathrm{H}$, $\left.\mathrm{CH}_{2}\right) ;{ }^{13} \mathrm{C} \mathrm{NMR}\left(75 \mathrm{MHz}, \mathrm{CDCl}_{3}\right) \delta 165.0,151.4,147.8$, 144.3, 139.1, 138.5, 130.6, 130.3, 129.2, 128.9, 128.2, $126.7,125.7,123.0,120.5,119.6,112.9,56.0,49.5,32.5$,
31.7, 21.8; HRMS (ESI-TOF) $\mathrm{m} / \mathrm{z}$ calculated for $[\mathrm{M}+\mathrm{H}]^{+}$: 428.1896, found: 428.1973 .

General synthetic procedures to obtain TS12, TS13, TS14, TS15, TS16 and TS17

To a round-bottom flask containing TS6 (1 equiv., $0.23 \mathrm{mmol})$ and the respective alkyl halide or benzyl halide (1.2 equiv., $0.27 \mathrm{mmol}$, TS12 (4-nitrobenzyl bromide), TS13 (4-clorobenzyl chloride), TS14 (4-methylbenzyl chloride), TS15 (methyl iodide), TS16 ( $n$-butyl bromide), and TS17 (benzyl bromide)) in water $(3 \mathrm{~mL})$, TBAB (1 equiv., $0.23 \mathrm{mmol}$ ) and $\mathrm{K}_{2} \mathrm{CO}_{3}$ (2 equiv., $0.45 \mathrm{mmol}$ ) were added. The reaction mixtures were stirred at room temperature for $36 \mathrm{~h}$. After, extractions with DCM (3x) were performed for each reaction, and the combined organic layers were dried over $\mathrm{MgSO}_{4}$ and evaporated under reduced pressure. The crude products were purified by silica gel column chromatography (hexane/EtOAc 7:3) to furnish TS12, TS13, TS14, TS15, TS16 and TS17.

1-(3-\{3-Methoxy-4-[(4-nitrophenyl)methoxy]phenyl\}propyl)4-phenyl-1H-1,2,3-triazole (TS12)

Yellow solid, yield $45 \%$, m.p. $125-130{ }^{\circ} \mathrm{C}$; IR (ATR) $\bar{v}_{\max } / \mathrm{cm}^{-1} 3122,3062,2915,2848,1604,1589,1512$, 1345,1463 ; ${ }^{1} \mathrm{H}$ NMR $\left(300 \mathrm{MHz}, \mathrm{CDCl}_{3}\right) \delta 8.25-8.19$ (m, 2H, Ar-H), 7.85-7.79 (m, 2H, Ar-H), $7.71(\mathrm{~s}, 1 \mathrm{H}$, triazole-H), 7.63-7.57 (m, 2H, Ar-H), 7.46-7.38 (m, 2H, Ar-H), 7.36-7.24 (m, 1H, Ar-H), 6.79-6.64 (m, 3H, Ar-H), $5.18\left(\mathrm{~s}, 2 \mathrm{H}, \mathrm{OCH}_{2}\right), 4.40\left(\mathrm{t}, 2 \mathrm{H}, J 7.1 \mathrm{~Hz}, \mathrm{CH}_{2} \mathrm{~N}\right), 3.89$ (s, $\left.3 \mathrm{H}, \mathrm{OCH}_{3}\right), 2.63\left(\mathrm{t}, 2 \mathrm{H}, J 7.4 \mathrm{~Hz}, \mathrm{CH}_{2}\right), 2.27(\mathrm{~m}, 2 \mathrm{H}$, $\left.J 7.1 \mathrm{~Hz}, \mathrm{CH}_{2}\right) ;{ }^{13} \mathrm{C} \mathrm{NMR}\left(75 \mathrm{MHz}, \mathrm{CDCl}_{3}\right) \delta 149.9,147.8$, 147.5, 146.0, 144.9, 134.3, 130.6, 128.9, 128.2, 127.5, 125.7, 123.8, 120.6, 119.5, 114.7, 112.5, 70.1, 56.0, 49.5, $32.2,31.8$; HRMS (ESI-TOF) $\mathrm{m} / \mathrm{z}$ calculated for $[\mathrm{M}+\mathrm{H}]^{+}$: 444.1797, found: 445.1872 .

1-(3-\{4-[(4-Chlorophenyl)methoxy]-3-methoxyphenyl\} propyl)-4-phenyl-1H-1,2,3-triazole (TS13)

White solid, yield $61 \%$, m.p. $90-95{ }^{\circ} \mathrm{C}$; IR (ATR) $\bar{v}_{\max } / \mathrm{cm}^{-1} 3120,3092,3054,2933,2894,2850,1589$, 1513, 1463, 1263, 1232; ${ }^{1} \mathrm{H}$ NMR (300 MHz, $\left.\mathrm{CDCl}_{3}\right) \delta$ $7.82(\mathrm{~d}, 2 \mathrm{H}, J 7.8 \mathrm{~Hz}$, Ar-H), $7.71(\mathrm{~s}, 1 \mathrm{H}$, triazole-H), 7.47-7.29 (m, 7H, Ar-H), 6.82-6.63 (m, 3H, Ar-H), 5.07 (s, $\left.2 \mathrm{H}, \mathrm{OCH}_{2}\right), 4.39\left(\mathrm{t}, 2 \mathrm{H}, J 7.0 \mathrm{~Hz}, \mathrm{CH}_{2} \mathrm{~N}\right), 3.87(\mathrm{~s}, 3 \mathrm{H}$, $\mathrm{OCH}_{3}$ ), 2.63 (t, $2 \mathrm{H}, J 7.4 \mathrm{~Hz}, \mathrm{CH}_{2}$ ), 2.34-2.19 (m, 2H, $\left.\mathrm{CH}_{2}\right) ;{ }^{13} \mathrm{C} \mathrm{NMR}\left(75 \mathrm{MHz}, \mathrm{CDCl}_{3}\right) \delta 149.8,147.8,146.4$, 135.8, 133.7, 133.6, 130.6, 128.9, 128.7 (2C), 128.2, 125.7, 120.3, 119.5, 114.5, 112.4, 70.5, 56.0, 49.5, 32.1, 31.8; HRMS (ESI-TOF) $\mathrm{m} / \mathrm{z}$ calculated for $[\mathrm{M}+\mathrm{H}]^{+}: 434.1557$, found: 434.1628. 
1-(3-\{3-Methoxy-4-[(4-methylphenyl)methoxy]phenyl\} propyl)-4-phenyl-1 $\mathrm{H}$-1,2,3-triazole (TS14)

Light yellow solid, yield $57 \%$, m.p. $88-92{ }^{\circ} \mathrm{C}$; IR (ATR) $\bar{v}_{\max } / \mathrm{cm}^{-1} 3131,3052,2920,2871,2853,1606$, $1589,1514,1465,1381,1261,1224 ;{ }^{1} \mathrm{H}$ NMR $(300 \mathrm{MHz}$, $\left.\mathrm{CDCl}_{3}\right) \delta$ 7.88-7.79 (m, 2H, Ar-H), $7.70(\mathrm{~s}, 1 \mathrm{H}$, triazole-H), 7.47-7.39 (m, 2H, Ar-H), 7.35-7.26 (m, 2H, Ar-H), 7.16 (d, 2H, J 7.8 Hz, Ar-H), 6.85-6.78 (m, 1H, Ar-H), 6.72 (d, $1 \mathrm{H}, J 2.0 \mathrm{~Hz}, \mathrm{Ar}-\mathrm{H}), 6.65$ (dd, 1H, J 8.1, $2.0 \mathrm{~Hz}, \mathrm{Ar}-\mathrm{H})$, $5.08\left(\mathrm{~s}, 2 \mathrm{H}, \mathrm{OCH}_{2}\right), 4.38\left(\mathrm{t}, 2 \mathrm{H}, J 7.0 \mathrm{~Hz}, \mathrm{CH}_{2} \mathrm{~N}\right), 3.87$ (s, $\left.3 \mathrm{H}, \mathrm{OCH}_{3}\right), 2.61\left(\mathrm{t}, 2 \mathrm{H}, J 7.4 \mathrm{~Hz}, \mathrm{CH}_{2}\right), 2.34\left(\mathrm{~s}, 3 \mathrm{H}, \mathrm{CH}_{3}\right)$, $2.24\left(\mathrm{~m}, 2 \mathrm{H}, \mathrm{CH}_{2}\right) ;{ }^{13} \mathrm{C}$ NMR $\left(75 \mathrm{MHz}, \mathrm{CDCl}_{3}\right) \delta 149.8$, $147.8,146.8,137.5,134.2,133.2,130.7,129.2,128.9$, 128.2, 127.4, 125.7, 120.3, 119.6, 114.4, 112.4, 71.1, 56.0, 49.5, 32.1, 31.8, 21.2; HRMS (ESI-TOF) $\mathrm{m} / z$ calculated for $[\mathrm{M}+\mathrm{H}]^{+}:$414.2103, found: 414.2175.

1 - [3-(3,4-Dimethoxyphenyl)propyl]-4-phenyl1H-1,2,3-triazole (TS15)

White solid, yield 37\%, m.p. 98-105 ${ }^{\circ} \mathrm{C}$; IR (ATR) $\bar{v}_{\max } / \mathrm{cm}^{-1} 3130,3095,3070,3001,2927,2850,2829$, $1606,1588,1514,1463,1231,1258$; ' ${ }^{H} \mathrm{~N}$ NMR (300 MHz, $\left.\mathrm{CDCl}_{3}\right) \delta$ 7.87-7.78 (m, 2H, Ar-H), $7.71(\mathrm{~s}, 1 \mathrm{H}$, triazole-H), 7.46-7.40 (m, 2H, Ar-H), 7.35 (m, 1H, Ar-H), 6.83-6.69 (m, 3H, Ar-H), 4.40 (t, $\left.2 \mathrm{H}, J 7.0 \mathrm{~Hz}, \mathrm{CH}_{2} \mathrm{~N}\right), 3.86(\mathrm{~d}, 6 \mathrm{H}$, $\left.\mathrm{OCH}_{3}\right), 2.64\left(\mathrm{t}, 2 \mathrm{H}, J 7.4 \mathrm{~Hz}, \mathrm{CH}_{2}\right), 2.35-2.21(\mathrm{~m}, 2 \mathrm{H}$, $\left.\mathrm{CH}_{2}\right) ;{ }^{13} \mathrm{C}$ NMR $\left(75 \mathrm{MHz}, \mathrm{CDCl}_{3}\right) \delta 149.0,147.8,147.6$, 132.7, 130.6, 128.9, 128.2, 125.7, 120.3, 119.5, 111.8, 111.4, 55.9 (2C), 49.5, 32.1, 31.9; HRMS (ESI-TOF) $\mathrm{m} / \mathrm{z}$ calculated for $[\mathrm{M}+\mathrm{H}]^{+}: 324.1634$, found: 324.1705 .

1-[3-(4-Butoxy-3-methoxyphenyl)propyl]-4-phenyl1H-1,2,3-triazole (TS16)

White solid, yield 53\%, m.p. $67-74{ }^{\circ} \mathrm{C}$; IR (ATR) $\bar{v}_{\max } / \mathrm{cm}^{-1} 3114,3084,3063,2931,2867,1606,1588$, 1514, 1463, 1257, 1231; ${ }^{1} \mathrm{H}$ NMR (300 MHz, $\mathrm{CDCl}_{3}$ ) $\delta$ 7.85-7.80 (m, 2H, Ar-H), $7.71(\mathrm{~s}, 1 \mathrm{H}$, triazole- $\mathrm{H}), 7.42(\mathrm{t}$, $2 \mathrm{H}$, J 7.4 Hz, Ar-H), 7.33 (m, 1H, Ar-H), 6.84-6.67 (m, 3H, Ar-H), $4.40\left(\mathrm{t}, 2 \mathrm{H}, J 7.0 \mathrm{~Hz}, \mathrm{CH}_{2} \mathrm{~N}\right), 3.98\left(\mathrm{t}, 2 \mathrm{H}, \mathrm{CH}_{2} \mathrm{O}\right.$ ), $3.85\left(\mathrm{~s}, 3 \mathrm{H}, \mathrm{OCH}_{3}\right), 2.63$ (t, $\left.2 \mathrm{H}, J 7.3 \mathrm{~Hz}, \mathrm{CH}_{2}\right), 2.27$ (m, $\left.2 \mathrm{H}, J 7.1 \mathrm{~Hz}, \mathrm{CH}_{2}\right), 1.86-1.75\left(\mathrm{~m}, 2 \mathrm{H}, \mathrm{CH}_{2} \mathrm{O}\right), 1.56-1.41$ $\left(\mathrm{m}, 2 \mathrm{H}, \mathrm{CH}_{2}\right), 0.97\left(\mathrm{t}, 2 \mathrm{H}, \mathrm{CH}_{2}\right) ;{ }^{13} \mathrm{C}$ NMR $(75 \mathrm{MHz}$, $\left.\mathrm{CDCl}_{3}\right) \delta 149.5,147.8,147.2,132.7,130.6,128.9,128.2$, 125.7, 120.4, 119.6, 113.2, 112.3, 68.9, 56.1, 49.6, 32.1, $31.8,31.3,19.2$, 13.9; HRMS (ESI-TOF) $\mathrm{m} / \mathrm{z}$ calculated for $[\mathrm{M}+\mathrm{H}]^{+}:$366.2103, found: 366.2179 .

1-\{3-[4-(Benzyloxy)-3-methoxyphenyl]propyl\}-4-phenyl1H-1,2,3-triazole (TS17)

White solid, yield 50\%, m.p. $100-107{ }^{\circ} \mathrm{C}$; IR (ATR) $\bar{v}_{\max } / \mathrm{cm}^{-1} 3113,3083,3030,2922,2869,2851,1589,1511$,
1461, 1261, 1223; ${ }^{1} \mathrm{H}$ NMR (300 MHz, $\left.\mathrm{CDCl}_{3}\right) \delta 7.83$ (dd, $2 \mathrm{H}, J 8.3,1.3 \mathrm{~Hz}, \mathrm{Ar}-\mathrm{H}), 7.71$ (s, 1H, triazole-H), 7.46-7.30 (m, 8H, Ar-H), $6.82(\mathrm{~d}, 1 \mathrm{H}, J 8.1 \mathrm{~Hz}, \mathrm{Ar}-\mathrm{H}), 6.73(\mathrm{~d}, 1 \mathrm{H}$, $J 2.0 \mathrm{~Hz}, \mathrm{Ar}-\mathrm{H}), 6.66$ (dd, $1 \mathrm{H}, J 8.1,2.0 \mathrm{~Hz}, \mathrm{Ar}-\mathrm{H}), 5.12$ (s, $\left.2 \mathrm{H}, \mathrm{CH}_{2} \mathrm{O}\right), 4.39\left(\mathrm{t}, 2 \mathrm{H}, \mathrm{CH}_{2} \mathrm{~N}\right), 3.88\left(\mathrm{~s}, 3 \mathrm{H}, \mathrm{OCH}_{3}\right), 2.63(\mathrm{t}$, $\left.2 \mathrm{H}, \mathrm{CH}_{2}\right), 2.27$ (q, 2H, $\left.\mathrm{CH}_{2}\right) ;{ }^{13} \mathrm{C} \mathrm{NMR}\left(75 \mathrm{MHz}, \mathrm{CDCl}_{3}\right.$ ) $\delta 149.8,147.7,146.8,137.3,133.4,130.5,128.9,128.5$, 128.2, 127.8, 127.3, 125.7, 120.3, 119.6, 114.4, 112.4, 71.2, 56.1, 49.6, 32.1, 31.8; HRMS (ESI-TOF) $\mathrm{m} / \mathrm{z}$ calculated for $[\mathrm{M}+\mathrm{H}]^{+}: 400.1946$, found: 400.2019 .

General synthetic procedures to obtain TS18, TS19 and TS20

The respective benzenesulfonyl chloride (1.01 equiv., $0.23 \mathrm{mmol}$, TS18 (benzenesulfonyl chloride), TS19 (4-toluenesulfonyl chloride) and TS20 (4-nitrobenzenesulfonyl chloride)) in THF $(0.33 \mathrm{~mL})$ was added dropwise to the round-bottom flask containing TS6 (1 equiv., $0.23 \mathrm{mmol}$ ) in THF $(0.2 \mathrm{~mL})$ and $\mathrm{K}_{2} \mathrm{CO}_{3} 10 \% \mathrm{~m} / \mathrm{m}$ ( 1.88 equiv., $0.42 \mathrm{mmol}$ ) at $0{ }^{\circ} \mathrm{C}$. The reactions were stirred at room temperature for $2 \mathrm{~h}$. After, EtOAc $(4 \mathrm{~mL})$ was added, and the mixtures were washed with distilled water $(3 \times 2 \mathrm{~mL})$. The organic layers were dried over $\mathrm{MgSO}_{4}$ and evaporated under reduced pressure. The crude products were purified by silica gel column chromatography (hexane/ EtOAc 7:3) to furnish TS18, TS19 and TS20.

2-Methoxy-4-[3-(4-phenyl-1H-1,2,3-triazol-1-yl)propyl] phenyl benzenesulfonate (TS18)

Light brown oil, yield 90\%, IR (ATR) $\bar{v}_{\max } / \mathrm{cm}^{-1} 3140$, 3061, 3004, 2931, 2879, 2854, 1603, 1506, 1464, 1364, $1289,1278,1175$; ${ }^{1} \mathrm{H}$ NMR (300 MHz, $\left.\mathrm{CDCl}_{3}\right) \delta$ 7.91-7.79 $(\mathrm{m}, 4 \mathrm{H}, \mathrm{Ar}-\mathrm{H}), 7.74(\mathrm{~s}, 1 \mathrm{H}$, triazole- $\mathrm{H}), 7.68-7.59(\mathrm{~m}, 1 \mathrm{H}$, Ar-H), 7.54-7.38 (m, 4H, Ar-H), 7.37-7.29 (m, 1H, Ar-H), 7.06 (d, 1H, J 8.2 Hz, Ar-H), 6.71 (dd, 1H, J 8.2, $1.9 \mathrm{~Hz}$, Ar-H), 6.65 (d, 1H, J 1.9 Hz, Ar-H), 4.39 (t, $2 \mathrm{H}, J 6.9 \mathrm{~Hz}$, $\left.\mathrm{CH}_{2} \mathrm{~N}\right), 3.50\left(\mathrm{~s}, 3 \mathrm{H}, \mathrm{OCH}_{3}\right), 2.63\left(\mathrm{t}, 2 \mathrm{H}, J 7.6 \mathrm{~Hz}, \mathrm{CH}_{2}\right)$, 2.33-2.18 (m, $\left.2 \mathrm{H}, \mathrm{CH}_{2}\right) ;{ }^{13} \mathrm{C}$ NMR $\left(75 \mathrm{MHz}, \mathrm{CDCl}_{3}\right)$ $\delta$ 151.7, 147.9, 140.6, 136.8, 136.3, 133.9, 130.5, 128.9, 128.7, 128.6, 128.2, 125.7, 124.1, 120.4, 119.6, 112.9, 55.5, 49.4, 32.4, 31.6; HRMS (ESI-TOF) $\mathrm{m} / \mathrm{z}$ calculated for $[\mathrm{M}+\mathrm{H}]^{+}: 450.1409$, found: 450.1486 .

2-Methoxy-4-[3-(4-phenyl-1 $H$-1,2,3-triazol-1-yl)propyl] phenyl 4-methylbenzene-1-sulfonate (TS19)

Light yellow solid, yield 53\%, m.p. $115-120{ }^{\circ} \mathrm{C}$; IR (ATR) $\bar{v}_{\max } / \mathrm{cm}^{-1} 3141,3067,3008,2941,2922,2859$, 1604, 1594, 1506, 1465, 1360, 1291, 1269, 1171; ' ${ }^{\mathrm{H}} \mathrm{NMR}$ (300 MHz, $\left.\mathrm{CDCl}_{3}\right) \delta$ 7.85-7.78 (m, 2H, Ar-H), 7.75 (s, 1H, triazole-H), 7.75-7.70 (m, 2H, Ar-H), 7.46-7.35 (m, $2 \mathrm{H}$, 
Ar-H), 7.35-7.25 (m, 3H, Ar-H), 7.03 (d, 1H, J $8.2 \mathrm{~Hz}$, Ar-H), 6.69 (dd, 1H, J 8.2, 1.9 Hz, Ar-H), $6.65(\mathrm{~d}, 1 \mathrm{H}$, $J 1.9 \mathrm{~Hz}, \mathrm{Ar}-\mathrm{H}$ ), 4.37 (t, $\left.2 \mathrm{H}, J 6.9 \mathrm{~Hz}, \mathrm{CH}_{2} \mathrm{~N}\right), 3.52$ (s, $\left.3 \mathrm{H}, \mathrm{OCH}_{3}\right), 2.61\left(\mathrm{t}, 2 \mathrm{H}, J 7.5 \mathrm{~Hz}, \mathrm{CH}_{2}\right), 2.42\left(\mathrm{~s}, 3 \mathrm{H}, \mathrm{CH}_{3}\right)$, 2.30-2.17 (m, 2H, $\left.\mathrm{CH}_{2}\right) ;{ }^{13} \mathrm{C} \mathrm{NMR}\left(75 \mathrm{MHz}, \mathrm{CDCl}_{3}\right.$ ) $\delta$ 151.7, 147.8, 145.0, 140.5, 136.8, 133.3, 130.6, 129.4, 128.9, 128.6, 128.2, 125.7, 123.9, 120.3, 119.7, 113.0, 55.6, 49.4, 32.4, 31.5, 21.7; HRMS (ESI-TOF) $\mathrm{m} / \mathrm{z}$ calculated for $[\mathrm{M}+\mathrm{H}]^{+}:$464.1566, found: 464.1733 .

2-Methoxy-4-[3-(4-phenyl-1H-1,2,3-triazol-1-yl)propyl] phenyl 4-nitrobenzene-1-sulfonate (TS20)

Yellow solid, yield 59\%, m.p. $110-115^{\circ} \mathrm{C}$; IR (ATR) $\bar{v}_{\max } / \mathrm{cm}^{-1} 3133,3102,3065,3033,3005,2927,2856$, 1603, 1532, 1506, 1464, 1381, 1348, 1288, 1260, 1179; ${ }^{1} \mathrm{H}$ NMR (300 MHz, $\left.\mathrm{CDCl}_{3}\right) \delta 8.37-8.30$ (m, 2H, Ar-H), 8.10-8.03 (m, 2H, Ar-H), 7.84-7.78 (m, 2H, Ar-H), 7.74 (s, $1 \mathrm{H}$, triazole-H), 7.45-7.37 (m, 2H, Ar-H), 7.35-7.30 (m, $1 \mathrm{H}, \mathrm{Ar}-\mathrm{H}), 7.12$ (d, 1H, J 8.2 Hz, Ar-H), 6.77-6.72 (m, 1H, Ar-H), 6.67 (d, 1H, J 1.8 Hz, Ar-H), 4.39 (t, $2 \mathrm{H}, J 6.9 \mathrm{~Hz}$, $\left.\mathrm{CH}_{2} \mathrm{~N}\right), 3.50\left(\mathrm{~s}, 3 \mathrm{H}, \mathrm{OCH}_{3}\right), 2.67-2.60\left(\mathrm{t}, 2 \mathrm{H}, \mathrm{CH}_{2}\right), 2.31-$ $2.19\left(\mathrm{~m}, 2 \mathrm{H}, \mathrm{CH}_{2}\right) ;{ }^{13} \mathrm{C} \mathrm{NMR}\left(75 \mathrm{MHz}, \mathrm{CDCl}_{3}\right) \delta 151.2$, $150.8,147.9,142.0,141.3,136.4,130.5,129.9,128.9$, 128.3, 125.7, 124.0, 123.9, 120.7, 119.6, 113.1, 55.5, 49.4, 32.4, 31.5; HRMS (ESI-TOF) $\mathrm{m} / \mathrm{z}$ calculated for $[\mathrm{M}+\mathrm{H}]^{+}$: 495.1260, found: 495.1333 .

\section{General synthetic procedures to obtain TS21 and TS22}

A mixture of TS6 ( 1 equiv., $0.26 \mathrm{mmol}$ ) in $\mathrm{CHCl}_{3}$ $(4 \mathrm{~mL}), \mathrm{K}_{2} \mathrm{CO}_{3} 10 \% \mathrm{~m} / \mathrm{v}$ (8.8 equiv., $\left.2.29 \mathrm{mmol}\right)$ and TBAB ( 0.3 equiv., $0.08 \mathrm{mmol}$ ) was added dropwise from an addition funnel to a round-bottom flask containing 2,3,4,6-tetra- $O$-acethyl-alpha-D-glucopyranosyl bromide or 2,3,4,6-tetra- $O$-acetyl-alpha-D-galactopyranosyl bromide (1.1 equiv., $0.29 \mathrm{mmol}$ ) at room temperature. Additional 0.5 equiv. of peracetylated glycosyl or galactosyl bromide was added after 20 and $32 \mathrm{~h}$ of stirring at room temperature. Then, the mixtures were poured into ice water, and concentrated $\mathrm{HCl}$ was added until $\mathrm{pH}=4-5$. The organic layers were washed with distilled water $(3 \times 10 \mathrm{~mL})$, dried over $\mathrm{MgSO}_{4}$ and evaporated under reduced pressure. The crude products were purified by silica gel column chromatography (hexane/EtOAc 6:4) to furnish TS21 and TS22.

4-[3-(4-Phenyl-1 H-1,2,3-triazol-1-il)propyl]-2-methoxyphenyl-2,3,4,6-tetra- $O$-acetyl- $\beta$-D-glicopyranoside (TS21)

White solid, yield $34 \%$, m.p. $115-119{ }^{\circ} \mathrm{C}$; IR (ATR) $\bar{v}_{\max } / \mathrm{cm}^{-1} 3089,2990,2952,2924,2852,1747,1738$, $1595,1515,1467,1252,1217$; ${ }^{1} \mathrm{H}$ NMR $(300 \mathrm{MHz}$,
$\left.\mathrm{CDCl}_{3}\right) \delta$ 7.85-7.79 (m, 2H, Ar-H), $7.72(\mathrm{~s}, 1 \mathrm{H}$, triazole-H), 7.46-7.38 (m, 2H, Ar-H), 7.36-7.29 (m, 1H, Ar-H), 7.04 (d, $1 \mathrm{H}, J 8.0 \mathrm{~Hz}, \mathrm{Ar}-\mathrm{H}), 6.71$ (d, 1H, J 1.9 Hz, Ar-H), $6.68(\mathrm{dd}$, $1 \mathrm{H}, J$ 8.1, 2.0 Hz, Ar-H), 5.27-5.24 (m, 2H, CH), 5.19-5.11 $(\mathrm{m}, 1 \mathrm{H}, \mathrm{CH}), 4.92-4.86(\mathrm{~m}, 1 \mathrm{H}, \mathrm{CH}), 4.39(\mathrm{t}, 2 \mathrm{H}, J 7.0 \mathrm{~Hz}$, $\left.\mathrm{CH}_{2} \mathrm{~N}\right), 4.21\left(\mathrm{dd}, 2 \mathrm{H}, J 12.0,6.0 \mathrm{~Hz}, 2 \mathrm{H}, \mathrm{CH}_{2}\right), 3.79$ (s, $\left.3 \mathrm{H}, \mathrm{OCH}_{3}\right), 3.73(\mathrm{~m}, 1 \mathrm{H}, \mathrm{CH}), 2.63\left(\mathrm{t}, 2 \mathrm{H}, J 7.4 \mathrm{~Hz}, \mathrm{CH}_{2}\right)$, $2.26\left(\mathrm{~m}, 2 \mathrm{H}, J 7.0 \mathrm{~Hz}, \mathrm{CH}_{2}\right), 2.07-2.02\left(\mathrm{~m}, 12 \mathrm{H}, \mathrm{OCOCH}_{3}\right)$; ${ }^{13} \mathrm{C}$ NMR $\left(75 \mathrm{MHz}, \mathrm{CDCl}_{3}\right) \delta 170.6,170.3,169.4(2 \mathrm{C})$, $150.7,147.8,144.5,136.9,130.6,128.9,128.2,125.7$, $120.5,119.6,113.1,101.0,72.6,71.9,71.2,68.4,61.9$, 56.1, 49.5, 32.3, 31.7, 20.7, 20.7; HRMS (ESI-TOF) $\mathrm{m} / \mathrm{z}$ calculated for $[\mathrm{M}+\mathrm{H}]^{+}: 640.2428$, found: 640.2505 .

4-[3-(4-Phenyl-1 $H$-1,2,3-triazol-1-il)propyl]-2-methoxyphenyl-2,3,4,6-tetra- $O$-acetyl- $\beta$-D-galactopyranoside (TS22)

Light yellow oil, yield $35 \%$, IR (ATR) $\bar{v}_{\max } / \mathrm{cm}^{-1} 3137$, 2958, 2937, 2873, 1743, 1593, 1512, 1465, 1212; ${ }^{1} \mathrm{H}$ NMR $\left(300 \mathrm{MHz}, \mathrm{CDCl}_{3}\right) \delta$ 7.84-7.80 (m, 2H, Ar-H), $7.72(\mathrm{~s}, 1 \mathrm{H}$, triazole-H), 7.46-7.39 (m, 2H, Ar-H), 7.37-7.30 (m, $1 \mathrm{H}$, Ar-H), 7.05 (d, 1H, J 8.1 Hz, Ar-H), $6.72(\mathrm{~d}, 1 \mathrm{H}, J 2 \mathrm{~Hz}$, Ar-H), 6.68 (dd, 1H, J 8.1, 2.0 Hz, Ar-H), 5.51-5.40 (m, 2H, $\mathrm{CH}), 5.07(\mathrm{dd}, 1 \mathrm{H}, J 10.5,3.4 \mathrm{~Hz}, \mathrm{CH}), 4.84(\mathrm{~d}, 1 \mathrm{H}, J 8 \mathrm{~Hz}$, $\mathrm{CH}), 4.40\left(\mathrm{t}, 1 \mathrm{H}, J 7.0 \mathrm{~Hz}, \mathrm{CH}_{2} \mathrm{~N}\right), 4.22-4.09\left(\mathrm{~m}, 2 \mathrm{H}, \mathrm{CH}_{2}\right)$, $3.93(\mathrm{td}, 1 \mathrm{H}, \mathrm{CH}), 3.80$ (s, 3H, $\left.\mathrm{CH}_{3}\right), 2.64(\mathrm{t}, 2 \mathrm{H}, J 7.4 \mathrm{~Hz}$, $\left.\mathrm{CH}_{2}\right), 2.28\left(\mathrm{~m}, 1 \mathrm{H}, \mathrm{CH}_{2}\right), 2.17-2.00\left(\mathrm{~m}, 12 \mathrm{H}, \mathrm{OCOCH}_{3}\right)$; ${ }^{13} \mathrm{C}$ NMR $\left(75 \mathrm{MHz}, \mathrm{CDCl}_{3}\right) \delta 170.4,170.3,170.2,169.6$, 150.7, 147.8, 144.7, 136.8, 130.6, 128.9, 128.2, 125.7, $120.5,119.5,113.1,101.6,70.9,70.8,68.7,66.9,61.2$, 56.1, 49.5, 32.3, 31.7, 20.8, 20.7; HRMS (ESI-TOF) $\mathrm{m} / \mathrm{z}$ calculated for $[\mathrm{M}+\mathrm{H}]^{+}: 640.2428$, found: 640.2501 .

\section{Microdilution assay}

To assess the antimycobacterial potential of synthesized compounds, the broth microdilution assay (CLSI M07-A10, $2015)^{42}$ with the strains Mycobacterium abscessus (ATCC 19977), Mycobacterium fortuitum (ATCC 6841) and Mycobacterium massiliense (ATCC 48898) was adopted. Dilutions (dilution factor $=2$ ) in medium Mueller Hinton (MH) from dimethyl sulfoxide (DMSO) solutions of the test compounds were applied to obtain different concentrations. Therefore, eight concentrations at the range 2755-19.53 $\mu \mathrm{g} \mathrm{mL}^{-1}$ were tested for each compound. Mycobacterial suspensions at 0.5 McFarland scale were prepared from cultivated strains in medium Lowenstein-Jensen. To obtain the final inoculum solution at $5 \times 10^{5} \mathrm{CFU} \mathrm{mL}^{-1}, 50 \mathrm{~mL}$ of mycobacterial suspension was transferred to a test tube containing $9.95 \mathrm{~mL}$ of Mueller Hinton broth. $100 \mu \mathrm{L}$ of the final inoculum and $100 \mu \mathrm{L}$ of 
compound solution were distributed in each well of the microplate. It was incubated at $37{ }^{\circ} \mathrm{C}$ for $72 \mathrm{~h}$. For the reading step, the lowest concentration associated with complete visible inhibition of mycobacterial growth was defined as the MIC.

\section{Cytotoxicity assay}

The test compounds cytotoxicity were evaluated to Vero cells (kidney cells extracted from African green monkeys) employing the MTT (3-(4,5-dimethylthiazol2-yl)-2,5-diphenyltetrazolium bromide) tetrazolium reduction assay. The cell suspension of Vero cells at a concentration of $2.4 \times 106$ cells $\mathrm{mL}^{-1}$ was distributed in a microtiter plate, $90 \mathrm{~mL}$ in each well with $10 \mathrm{~mL}$ of test compounds at different concentrations: 50, 25, 12.5, 6.25, and $3.125 \mu \mathrm{g} \mathrm{mL}^{-1}$. The microtiter plate was incubated at $37^{\circ} \mathrm{C}$ in an incubator at $5 \% \mathrm{CO}_{2}$ for $48 \mathrm{~h}$. After, $10 \mu \mathrm{L}$ of MTT at $5 \mathrm{mg} \mathrm{mL}^{-1}$ was added and the cells incubated for $4 \mathrm{~h}$. To solubilize the formazan crystals, DMSO $(100 \mu \mathrm{L})$ was used. The plates were shaken for $5 \mathrm{~min}$, and absorbance for each sample was measured in a spectrophotometric microplate reader at $560 \mathrm{~nm}$. The percentage of cytotoxicity was calculated as [(A-B) / A $\times 100]$, where A and B are the absorbances of control and treated cells, respectively. Data were analyzed using linear regression to obtain values for $\mathrm{CC}_{50}$ (cytotoxic concentration for 50\%). Selectivity indexes were expressed as the ratio $\mathrm{CC}_{50} / \mathrm{MIC}$.

\section{Supplementary Information}

Supplementary data associated with this article $\left({ }^{1} \mathrm{H}\right.$, ${ }^{13} \mathrm{C}$, IR and HRMS spectra of the compounds) can be found in the supplementary material available free of charge at http://jbcs.sbq.org.br as PDF file.

\section{Acknowledgments}

This work was supported by the Coordenação de Aperfeiçoamento de Pessoal de Nível Superior, Brazil (CAPES), Financing Code 001. The authors also thank FAPEMIG for the scholarship and financial support (APQ01268-16).

\section{References}

1. Tor, Y.; Fair, R.; Perspect. Med. Chem. 2014, 6, 25.

2. Catry, B.; Dewulf, J.; Maes, D.; Pardon, B.; Callens, B.; Vanrobaeys, M.; Opsomer, G.; de Kruif, A.; Haesebrouck, F.; PLoS One 2016, 11, e0146488.

3. Lakshmanan, M.; Xavier, A. S.; J. Young Pharm. 2013, 5, 112.
4. Kakkar, A. K.; Dahiya, N.; Tuberculosis 2014, 94, 357.

5. El Helou, G.; Viola, G. M.; Hachem, R.; Han, X. Y.; Raad, I. I.; Lancet Infect. Dis. 2013, 13, 166.

6. Gnanenthiran, S. R.; Liu, E. Y. T.; Wilson, M.; Chung, T.; Gottlieb, T.; Heart, Lung Circ. 2017, 25, S277.

7. Kasperbauer, S. H.; De Groote, M. A.; Clin. Chest Med. 2015 , $36,67$.

8. Monego, F.; Duarte, R. S.; Nakatani, S. M.; Araújo, W. N.; Riediger, I. N.; Brockelt, S.; Souza, V.; Cataldo, J. I.; Dias, R. C. S.; Biondo, A. W.; Braz. J. Infect. Dis. 2011, 15, 436.

9. Blair, P.; Moshgriz, M.; Siegel, M.; J. Infect. Chemother. 2017, 23, 177.

10. Nie, W.; Duan, H.; Huang, H.; Lu, Y.; Bi, D.; Chu, N.; Int. J. Infect. Dis. 2014, 25, 170.

11. Wu, T. S.; Yang, C. H.; Brown-Elliott, B. A.; Chao, A. S.; Leu, H. S.; Wu, T. L.; Lin, C. S.; Griffith, D. E.; Chiu, C. H.; J. Microbiol., Immunol. Infect. 2016, 49, 955.

12. Darvishi, E.; Omidi, M.; Bushehri, A. A. S.; Golshani, A.; Smith, M. L.; PLoS One 2013, 8, e76028.

13. Wang, C.; Fan, Y.; J. Sci. Food Agric. 2014, 94, 677.

14. Jaganathan, S. K.; Mazumdar, A.; Mondhe, D.; Mandal, M.; Cell Biol. Int. 2011, 35, 607.

15. Coelho, C. M.; dos Santos, T.; Freitas, P. G.; Nunes, J. B.; Marques, M. J.; Padovani, C. G. D.; Júdice, W. A. S.; Camps, I.; da Silveira, N. J. F.; Carvalho, D. T.; Veloso, M. P.; J. Braz. Chem. Soc. 2018, 29, 715.

16. Andrade-Ochoa, S.; Nevárez-Moorillón, G. V.; SánchezTorres, L. E.; Villanueva-García, M.; Sánchez-Ramírez, B. E.; Rodríguez-Valdez, L. M.; Rivera-Chavira, B. E.; BMC Complementary Altern. Med. 2015, 15, 332.

17. Castagnolo, D.; Radi, M.; Dessì, F.; Manetti, F.; Saddi, M.; Meleddu, R.; De Logu, A.; Botta, M.; Bioorg. Med. Chem. Lett. 2009, 19, 2203.

18. Srivastava, S.; Bimal, D.; Bohra, K.; Singh, B.; Ponnan, P.; Jain, R.; Varma-Basil, M.; Maity, J.; Thirumal, M.; Prasad, A. K.; Eur. J. Med. Chem. 2018, 150, 268.

19. Xu, Z.; Song, X.-F.; Hu, Y.-Q.; Qiang, M.; Lv, Z.-S.; Eur. J. Med. Chem. 2017, 138, 66.

20. Zhang, S.; Xu, Z.; Gao, C.; Ren, Q. C.; Chang, L.; Lv, Z. S.; Feng, L. S.; Eur. J. Med. Chem. 2017, 138, 501.

21. Harbort, J. S.; De Voss, J. J.; Stok, J. E.; Bell, S. G.; Harmer, J. R. In Future Directions in Metalloprotein and Metalloenzyme Research, $1^{\text {st }}$ ed.; Hanson, G.; Berliner, L., eds.; Springer International Publishing: Cham, Switzerland, 2017, p. 121.

22. Seward, H. E.; Roujeinikova, A.; McLean, K. J.; Munro, A. W.; Leys, D.; J. Biol. Chem. 2006, 281, 39437.

23. Conner, K. P.; Woods, C. M.; Atkins, W. M.; Arch. Biochem. Biophys. 2011, 507, 56.

24. Rode, N. D.; Sonawane, A. D.; Nawale, L.; Khedkar, V. M.; Joshi, R. A.; Likhite, A. P.; Sarkar, D.; Joshi, R. R.; Chem. Biol. Drug Des. 2017, 90, 1206. 
25. Driscoll, M. D.; Mclean, K. J.; Cheesman, M. R.; Jowitt, T. A.; Howard, M.; Carroll, P.; Parish, T.; Munro, A. W.; Biochim. Biophys. Acta, Proteins Proteomics 2011, 1814, 76.

26. Molteni, V.; Li, X.; Nabakka, J.; Ellis, D. A.; Anaclerio, B.; Saez, E.; Wityak, J.; US patent 2005077124A2 2005.

27. Murie, V. E.; Marques, L. M. M.; Souza, G. E. P.; Oliveira, A. R. M.; Lopes, N. P.; Clososki, G. C.; J. Braz. Chem. Soc. 2016, 27, 1121.

28. Hemelaere, R.; Carreaux, F.; Carboni, B.; Eur. J. Org. Chem. 2015, 11, 2470.

29. Donohoe, T. J.; Kershaw, N. M.; Baron, R.; Compton, R. G.; Tetrahedron 2009, 65, 5377.

30. Kawatkar, S. P.; Keating, T. A.; Olivier, N. B.; Breen, J. N.; Green, O. M.; Guler, S. Y.; Hentemann, M. F.; Loch, J. T.; McKenzie, A. R.; Newman, J. V.; Otterson, L. G.; MartínezBotella, G.; J. Med. Chem. 2014, 57, 4584.

31. Vujjini, S. K.; Datla, V. R. K. R.; Badarla, K. R.; Vetukuri, V. N. K. V. P. R.; Bandichhor, R.; Kagga, M.; Cherukupally, P.; Tetrahedron Lett. 2014, 55, 3885.

32. Pereira, G. R.; Santos, L. J.; Luduvico, I.; Alves, R. B.; de Freitas, R. P.; Tetrahedron Lett. 2010, 51, 1022.

33. Ghosh, A. K.; Liu, C.; Org. Lett. 2001, 3, 635.

34. Kieć-Kononowicz, K.; Karolak-Wojciechowska, J.; Michalak, B.; Pękala, E.; Schumacher, B.; Müller, C. E.; Eur. J. Med. Chem. 2004, 39, 205.

35. Keraani, A.; Fischmeister, C.; Renouard, T.; Le Floch, M.; Baudry, A.; Bruneau, C.; Rabiller-Baudry, M.; J. Mol. Catal. A: Chem. 2012, 357, 73.
36. Pu, X.; Hu, J.; Zhao, Y.; Shi, Z.; ACS Catal. 2016, 6, 6692.

37. Wang, H.; Ma, Y.; Tian, H.; Yu, A.; Chang, J.; Wu, Y.; Tetrahedron 2014, 70, 2669.

38. Lei, X.; Jalla, A.; Abou Shama, M. A.; Stafford, J. M.; Cao, B.; Synthesis 2015, 47, 2578.

39. Conchie, J.; Levvy, G. A.; Marsh, C. A.; Adv. Carbohydr. Chem. 1957, 12, 157.

40. Zhu, Z. Y.; Cui, D.; Gao, H.; Dong, F. Y.; Liu, X. C.; Liu, F.; Chen, L.; Zhang, Y. M.; Eur. J. Med. Chem. 2016, 114, 8.

41. Bubb, W. A.; Concepts Magn. Reson., Part A 2003, 19A, 1.

42. Hatakeyama, S.; Ohama, Y.; Okazaki, M.; Nukui, Y.; Moriya, K.; BMC Infect. Dis. 2017, 17, 197.

43. Agertt, V. A.; Bonez, P. C.; Rossi, G. G.; Flores, V. C.; Siqueira, F. S.; Mizdal, C. R.; Marques, L. L.; de Oliveira, G. N. M.; de Campos, M. M. A.; BioMetals 2016, 29, 807.

44. Li, G.; Pang, H.; Guo, Q.; Huang, M.; Tan, Y.; Li, C.; Wei, J.; Xia, Y.; Jiang, Y.; Zhao, X.; Liu, H.; Zhao, L.-1.; Liu, Z.; Xu, D.; Wan, K.; Int. J. Antimicrob. Agents 2017, 49, 364.

45. Flores, V. C.; Siqueira, F. S.; Mizdal, C. R.; Bonez, P. C.; Agertt, V. A.; Stefanello, S. T.; Rossi, G. G.; Campos, M. M. A.; Microb. Pathog. 2016, 99, 229.

46. Daina, A.; Michielin, O.; Zoete, V.; Sci. Rep. 2017, 7, 42717.

47. Lipinski, C. A.; Lombardo, F.; Dominy, B. W.; Feeney, P. J.; Adv. Drug Delivery Rev. 1997, 23, 3.

Submitted: December 5, 2018 Published online: March 6, 2019 